\title{
The first biologically active synthetic analogues of FK228, the depsipeptide histone deacetylase inhibitor.
}

Alexander Yurek-George, Alexander Richard Liam Cecil, Alex Hon Kit Mo,

Shijun Wen, Helen Rogers, Satoko Maeda, Minoru Yoshida, Graham Packham, A. Ganesan*

School of Chemistry, University of Southampton, Southampton SO17 1BJ, United Kingdom.

Supporting Information

HPLC Data

S2

HRMS Data Table $\quad$ S5

${ }^{13}$ C NMR Data $\quad$ S6

$\begin{array}{ll}\text { Experimental } & \text { S24 }\end{array}$ 


\section{HPLC Data}

\begin{tabular}{|l|l|}
\hline Compound & Purity (HPLC) \\
\hline $\mathbf{8 a}$ & $98 \%$ \\
\hline $\mathbf{8 b}$ & $>98 \%$ \\
\hline $\mathbf{1 5 b}$ & $>98 \%$ \\
\hline
\end{tabular}

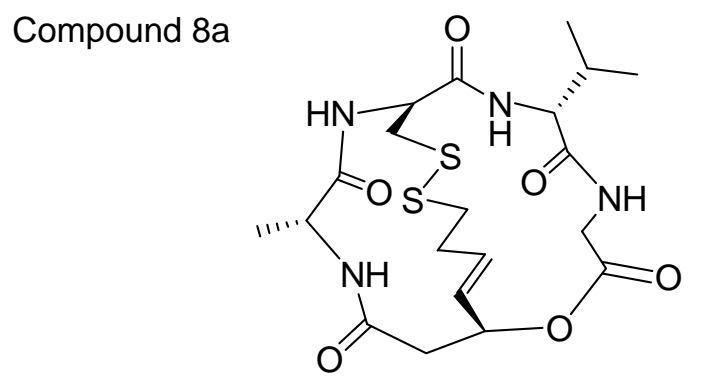

$8 a$

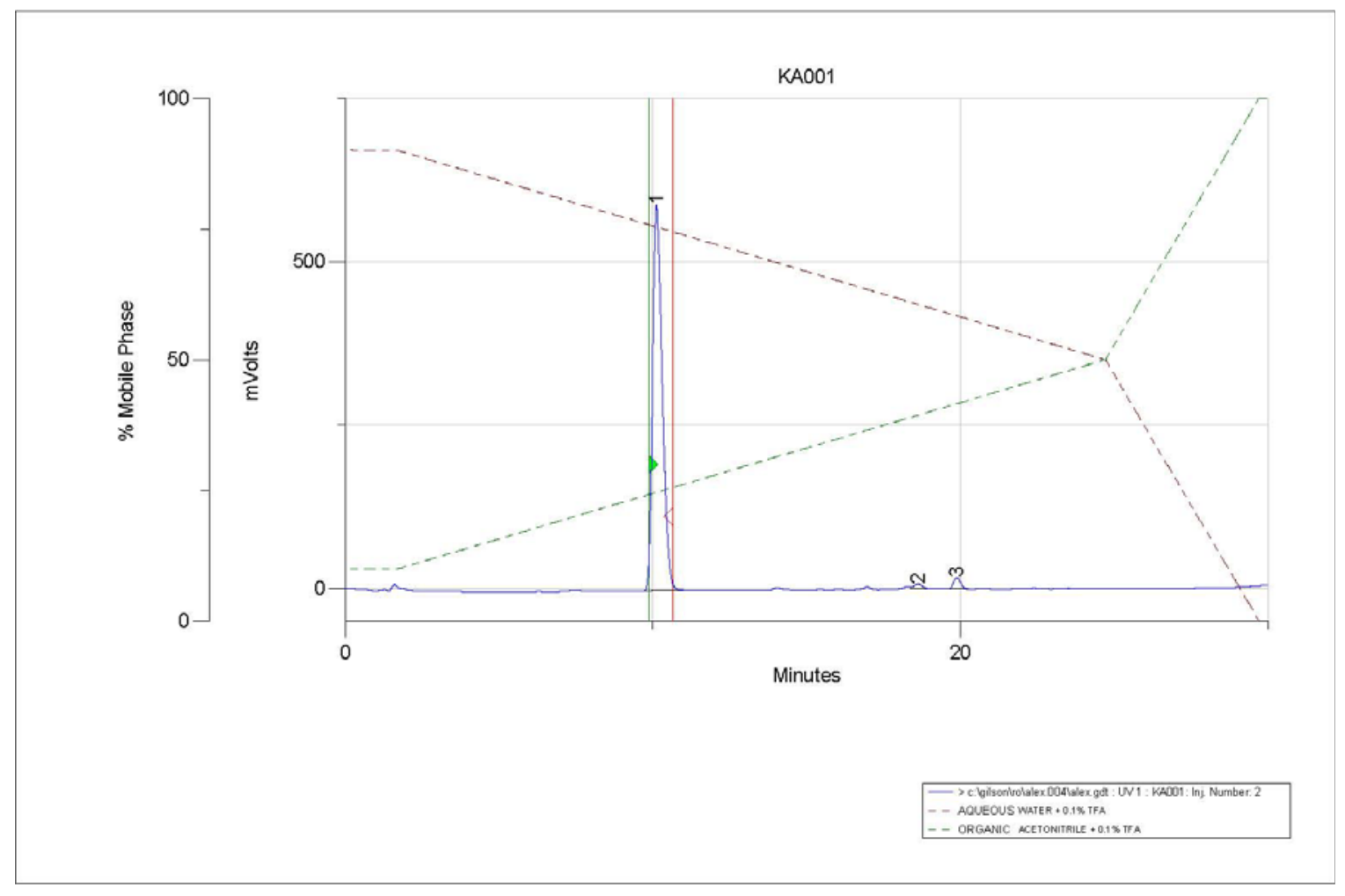

\begin{tabular}{|c|c|c|c|c|}
\hline $\begin{array}{c}\text { Sample } \\
\text { Description }\end{array}$ & Injection & R. Time & Area \% & Wavelength nm \\
\hline $8 \mathrm{a}$ & 2 & 10.12 & 98.1 & 220 \\
\hline
\end{tabular}

Summary:

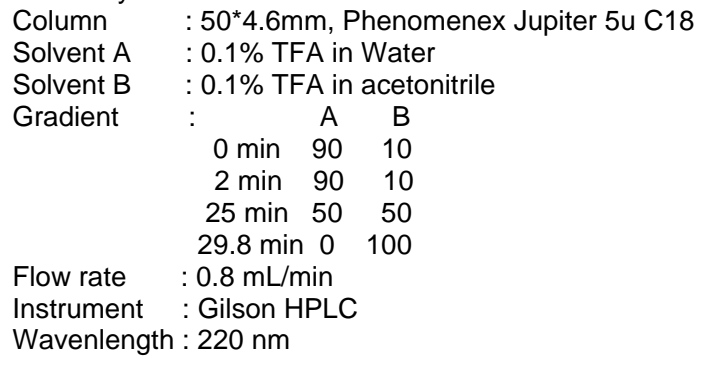




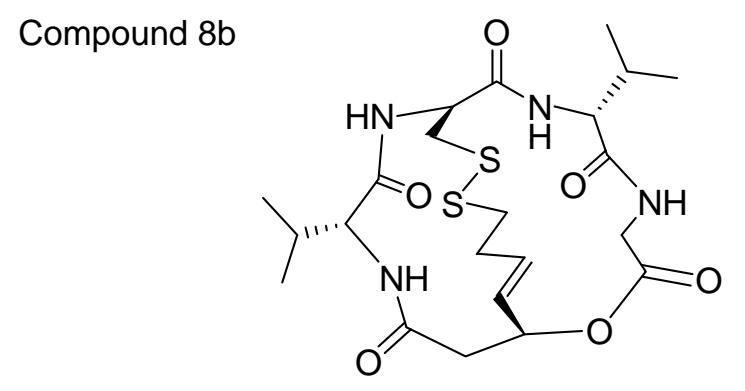

$8 b$

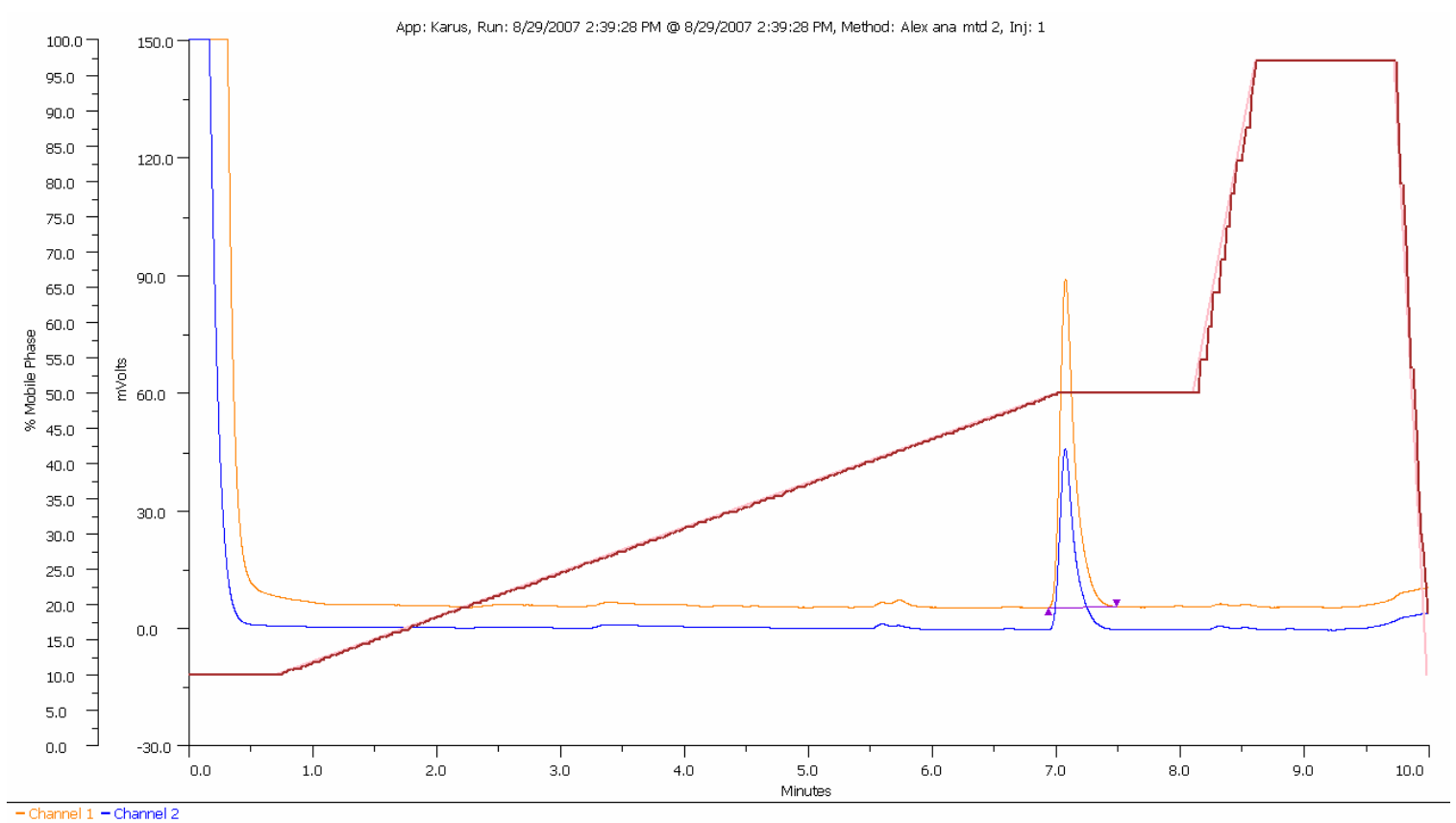

\begin{tabular}{|c|c|c|c|c|}
\hline $\begin{array}{c}\text { Sample } \\
\text { Description }\end{array}$ & Injection & R. Time & Area \% & Wavelength nm \\
\hline $8 \mathrm{~b}$ & 2 & 7.08 & 100 & 220 \\
\hline
\end{tabular}

Summary:

Column : : 125*4.6mm, Nucleodur 5u C18

Solvent A : : $0.1 \%$ TFA in Water

Solvent B : 0.1\% TFA in acetonitrile

Gradient : A B

$0 \min 90 \quad 10$

7 min $50 \quad 50$

8 min $50 \quad 50$

$8.5 \mathrm{~min} \quad 0 \quad 100$

Flow rate $: 2 \mathrm{~mL} / \mathrm{min}$

Instrument : Gilson HPLC

Wavenlength : Channel 1, $220 \mathrm{~nm}$; channel 2, $230 \mathrm{~nm}$ 


\section{Compound 15b}

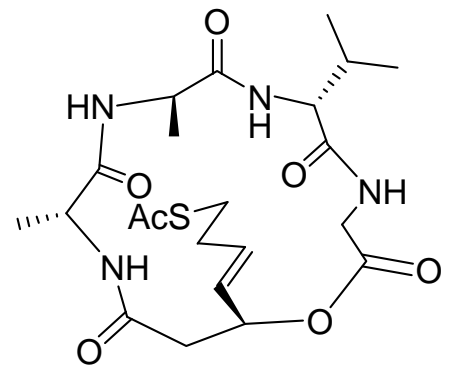

$15 b$

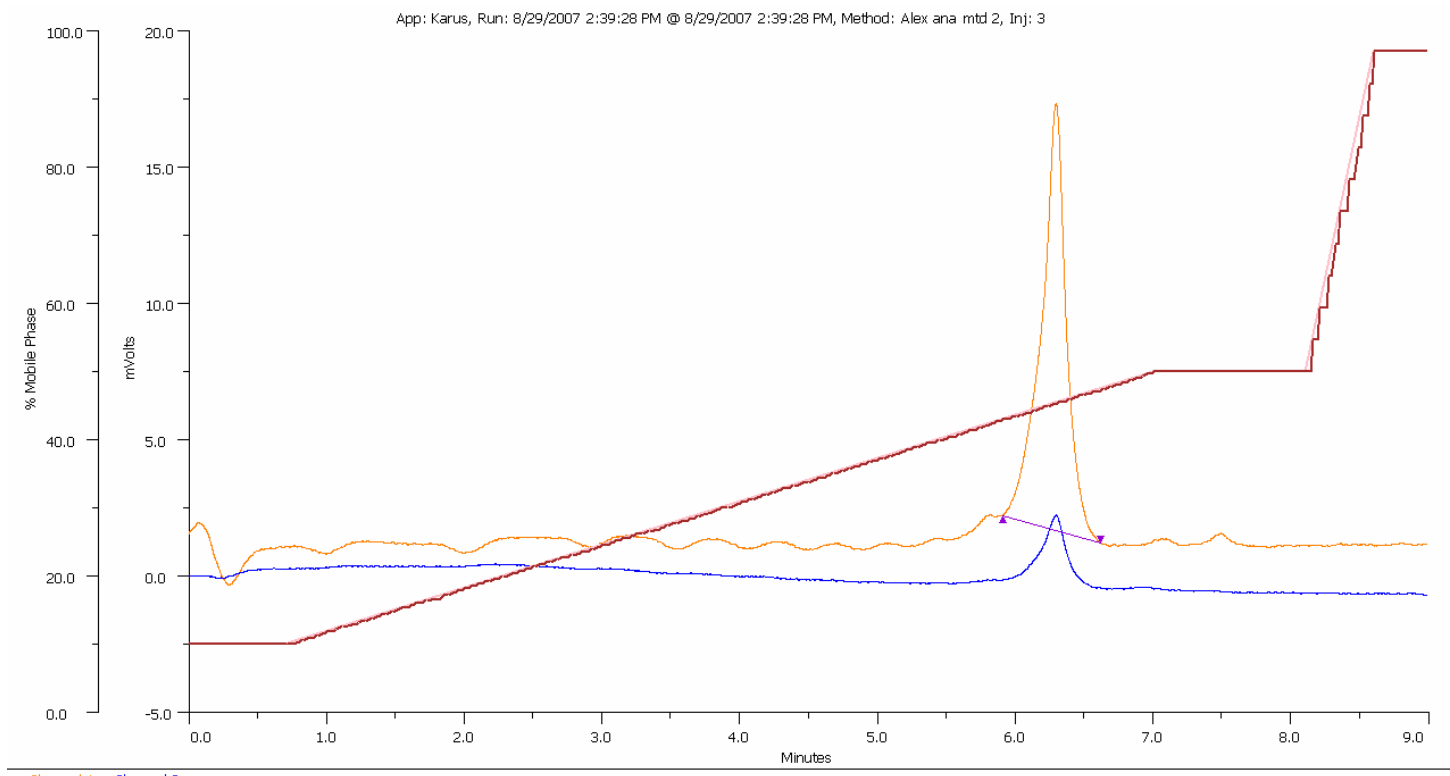

\begin{tabular}{|c|c|c|c|c|}
\hline $\begin{array}{c}\text { Sample } \\
\text { Description }\end{array}$ & Injection & R. Time & Area \% & Wavelength $\mathbf{n m}$ \\
\hline 15b & 3 & 6.29 & 100 & 220 \\
\hline
\end{tabular}

Summary:

Column : $125 * 4.6 \mathrm{~mm}$, Nucleodur 5u C18

Solvent A : 0.1\% TFA in Water

Solvent B $: 0.1 \%$ TFA in acetonitrile

Gradient : A B

$0 \min \quad 90 \quad 10$

$0.7 \min 90 \quad 10$

7 min $50 \quad 50$

$8 \mathrm{~min} \quad 50 \quad 50$

$8.5 \mathrm{~min} \quad 0 \quad 100$

Flow rate $: 2 \mathrm{~mL} / \mathrm{min}$

Instrument : Gilson HPLC

Wavenlength : Channel 1, $220 \mathrm{~nm}$; channel 2, $230 \mathrm{~nm}$ 
HRMS data for compounds with a MW $<1000$.

\begin{tabular}{|c|c|c|c|}
\hline Compound Number & Molecular Formula & Calculated MW & Found MW \\
\hline 3a & $\mathrm{C}_{48} \mathrm{H}_{50} \mathrm{~N}_{4} \mathrm{O}_{7} \mathrm{SNa}$ & 849.3292 & 849.3286 \\
\hline 3b & $\mathrm{C}_{50} \mathrm{H}_{54} \mathrm{~N}_{4} \mathrm{O}_{7} \mathrm{SNa}$ & 877.3605 & 877.3607 \\
\hline $\mathbf{7 a}$ & $\mathrm{C}_{58} \mathrm{H}_{60} \mathrm{~N}_{4} \mathrm{O}_{6} \mathrm{~S}_{2} \mathrm{Na}$ & 995.3846 & 995.3860 \\
\hline $\mathbf{8 a}$ & $\mathrm{C}_{20} \mathrm{H}_{30} \mathrm{~N}_{4} \mathrm{O}_{6} \mathrm{~S}_{2} \mathrm{Na}$ & 509.1499 & 509.1511 \\
\hline $\mathbf{8 b}$ & $\mathrm{C}_{22} \mathrm{H}_{34} \mathrm{~N}_{4} \mathrm{O}_{6} \mathrm{~S}_{2} \mathrm{Na}$ & 537.1812 & 537.1805 \\
\hline $\mathbf{9}$ & $\mathrm{C}_{21} \mathrm{H}_{34} \mathrm{~N}_{4} \mathrm{O}_{7} \mathrm{~S}_{2} \mathrm{Na}$ & 541.1761 & 541.1766 \\
\hline $\mathbf{1 0}$ & $\mathrm{C}_{13} \mathrm{H}_{24} \mathrm{~N}_{2} \mathrm{O}_{5} \mathrm{Na}$ & 311.1577 & 311.1578 \\
\hline $\mathbf{1 1}$ & $\mathrm{C}_{16} \mathrm{H}_{29} \mathrm{~N}_{3} \mathrm{O}_{6} \mathrm{Na}$ & 382.1949 & 382.1948 \\
\hline $\mathbf{1 2}$ & $\mathrm{C}_{19} \mathrm{H}_{34} \mathrm{~N}_{4} \mathrm{O}_{7} \mathrm{Na}$ & 453.2320 & 453.2327 \\
\hline $\mathbf{1 3}$ & $\mathrm{C}_{40} \mathrm{H}_{50} \mathrm{~N}_{4} \mathrm{O}_{7} \mathrm{SNa}$ & 753.3292 & 753.3307 \\
\hline $\mathbf{1 4}$ & $\mathrm{C}_{39} \mathrm{H}_{46} \mathrm{~N}_{4} \mathrm{O}_{6} \mathrm{SNa}$ & 721.3030 & 521.3017 \\
\hline $\mathbf{1 5 a}$ & $\mathrm{C}_{20} \mathrm{H}_{32} \mathrm{~N}_{4} \mathrm{O}_{6} \mathrm{SNa}$ & 479.1935 & \\
\hline $\mathbf{1 5 b}$ & $\mathrm{C}_{22} \mathrm{H}_{34} \mathrm{~N}_{4} \mathrm{O}_{7} \mathrm{SNa}$ & 521.2040 & \\
\hline & & & 5.1937 \\
\hline & & & \\
\hline & & & \\
\hline & & & \\
\hline & & & \\
\hline
\end{tabular}




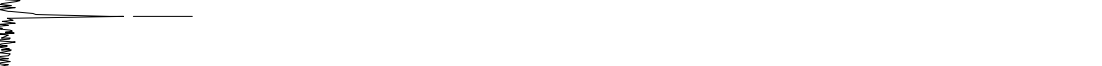




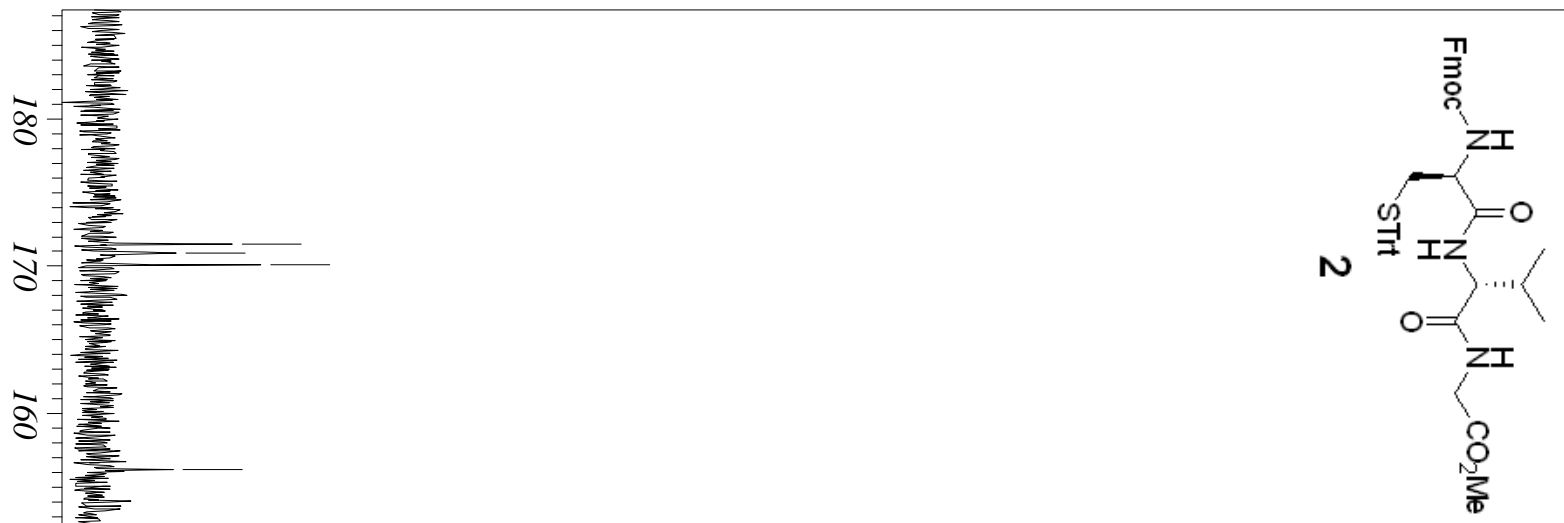

जั

$\vec{\Delta}$

143.6383

143.5030

141.1750

129.3708

127.9604

127.6320

126.9655

126.8592

- 124.8693

N

119.8269

$\Xi$

$\overline{8}$

옹

8

$\infty$

77.4688

77.1500

76.8312

$\checkmark$

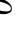

66.9589

8

$-58.2361$

of

$-53.8603$

51.9766

49.3491

49.1366

48.9241

48.7116

48.4991

48.2866

48.0740

46.9245

40.5491

33.5651

30.2324

N

$-18.8532$ 17.2497

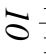

.

.

o 


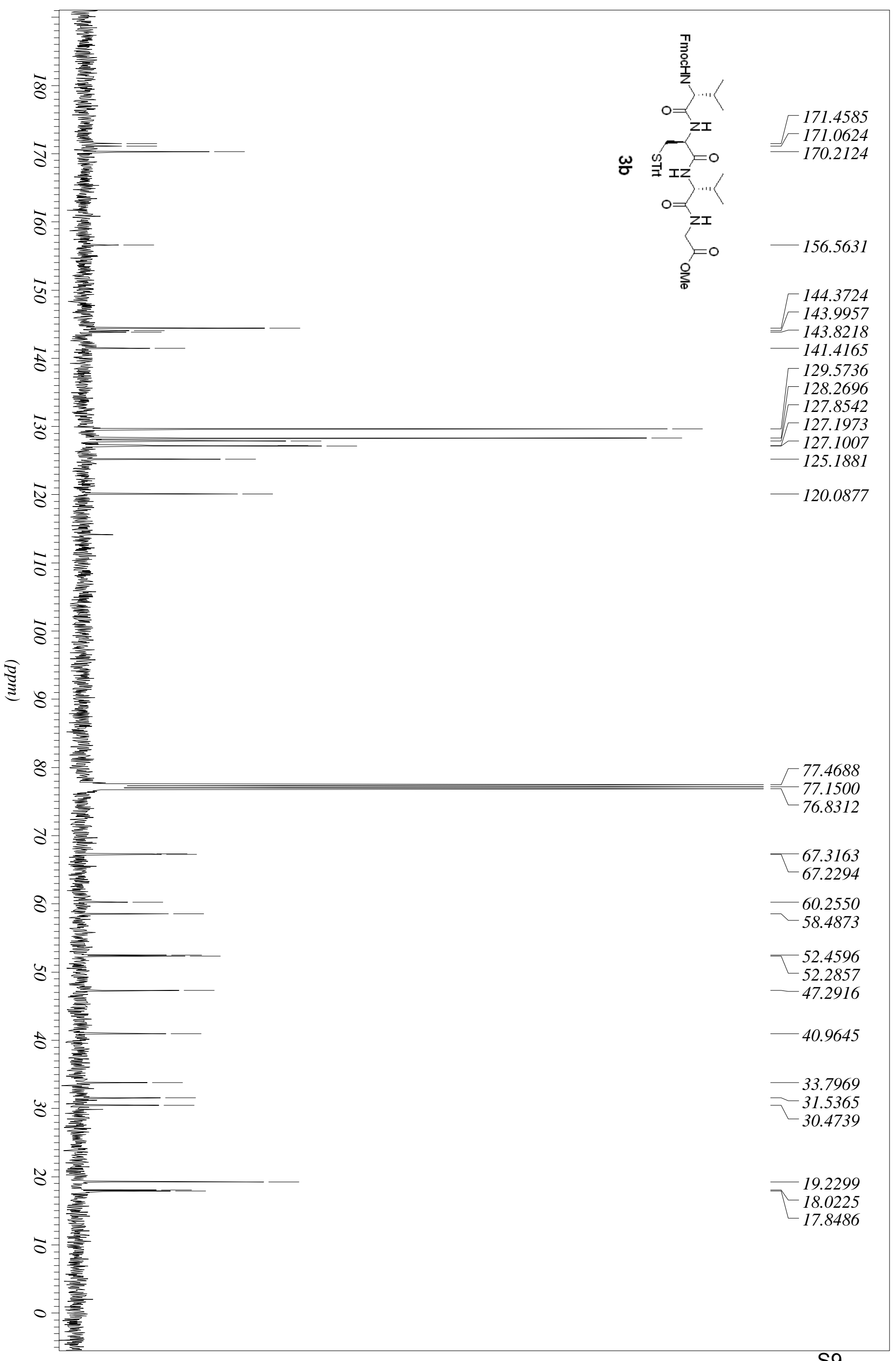




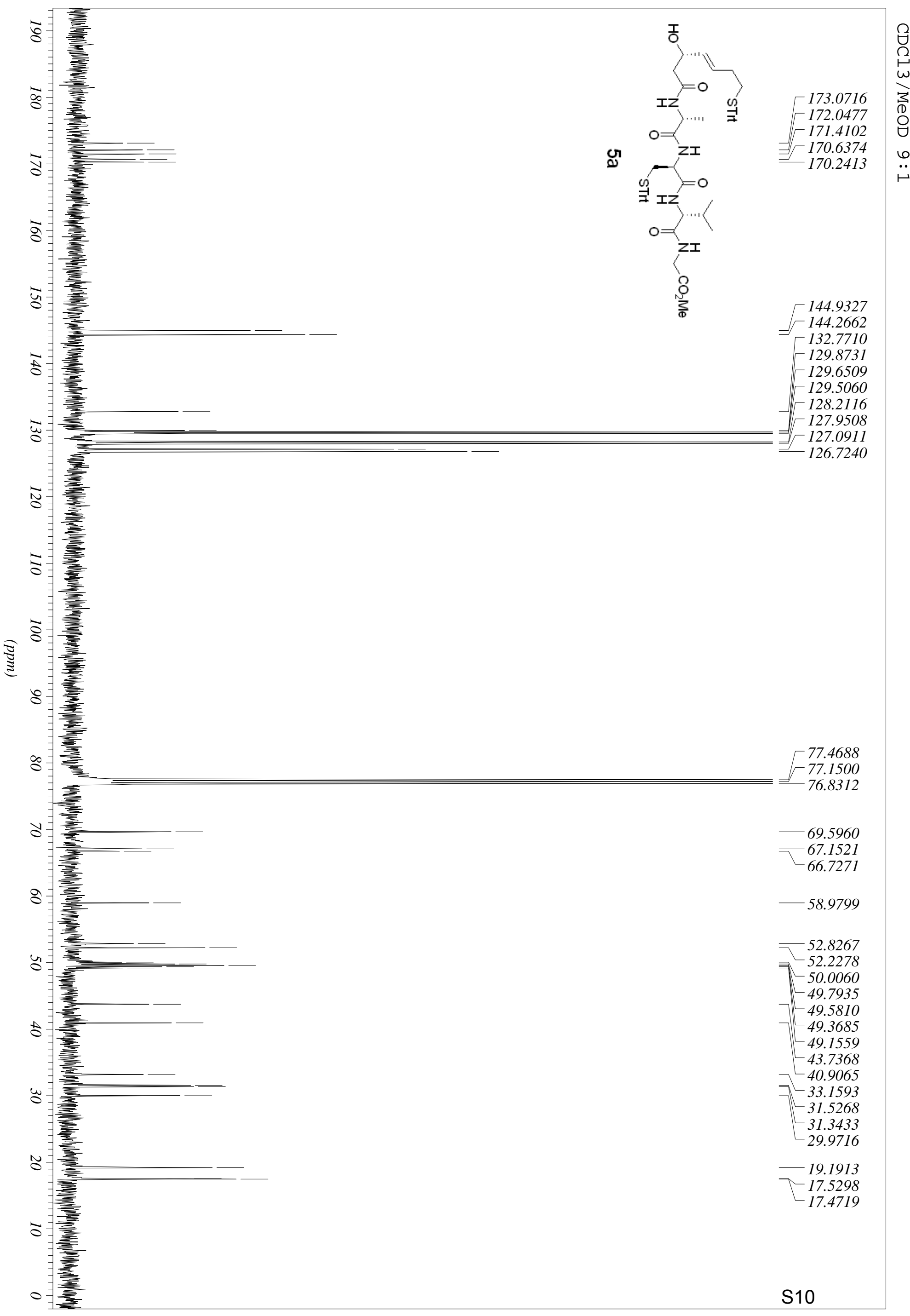




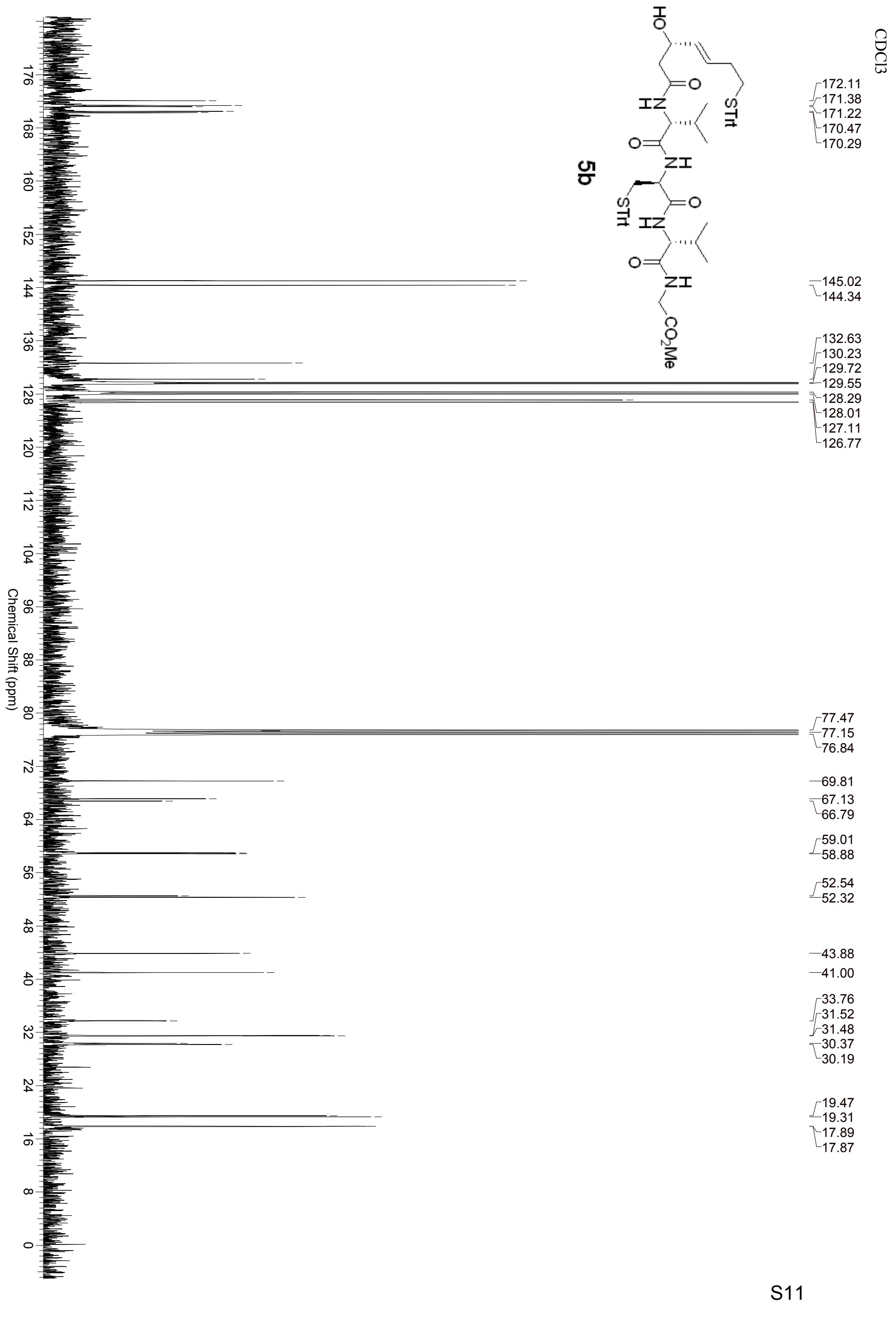




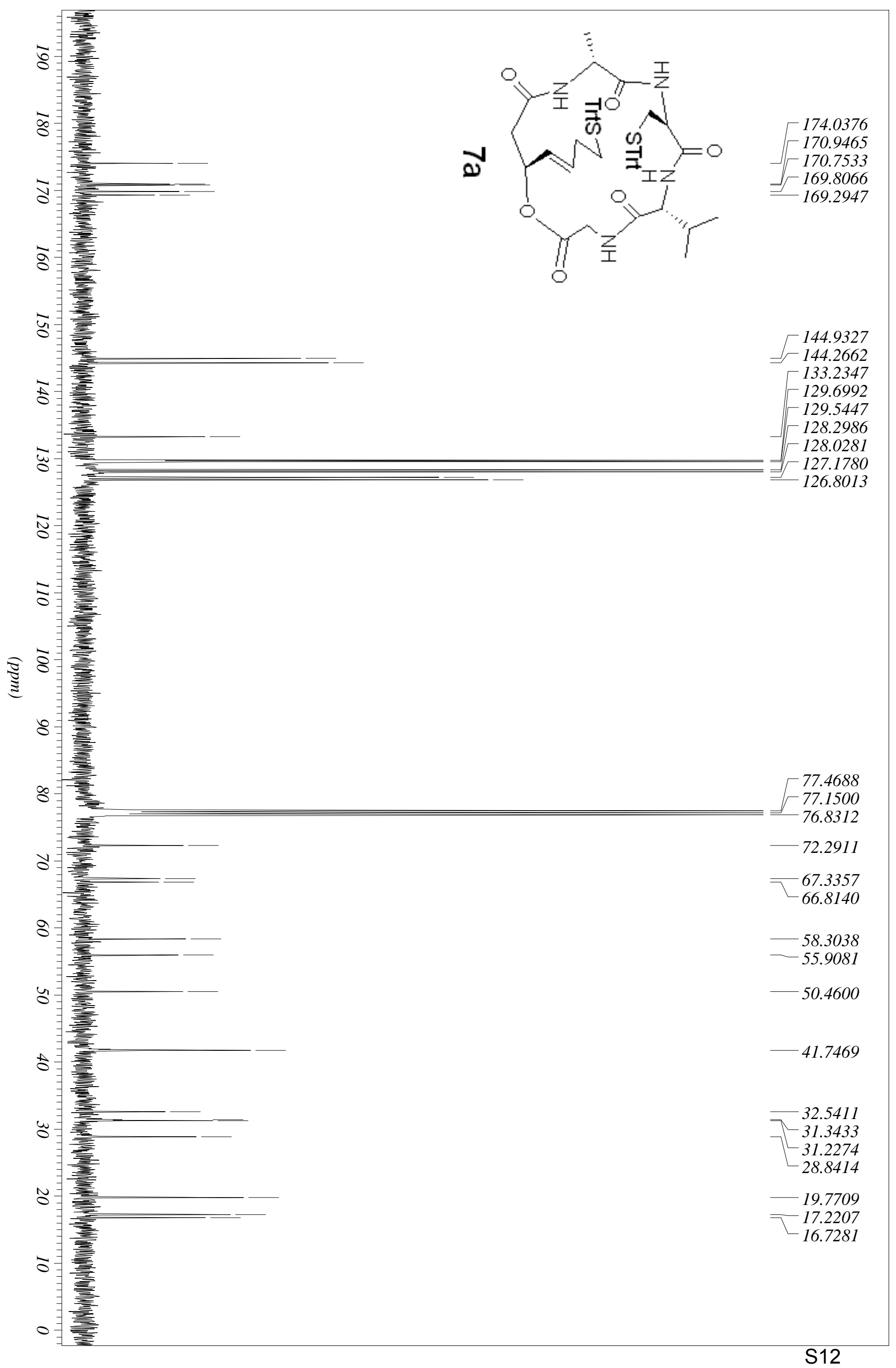




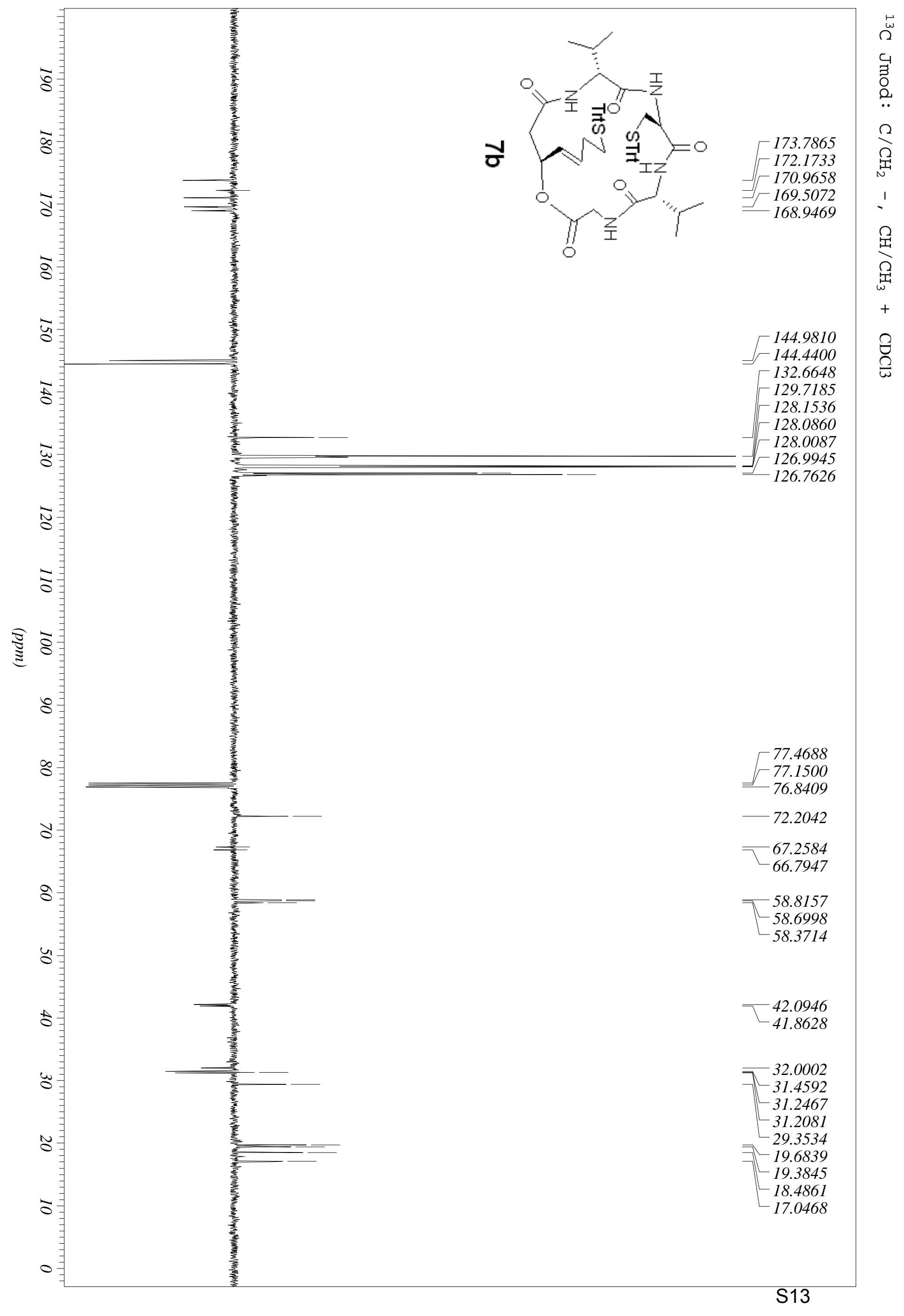




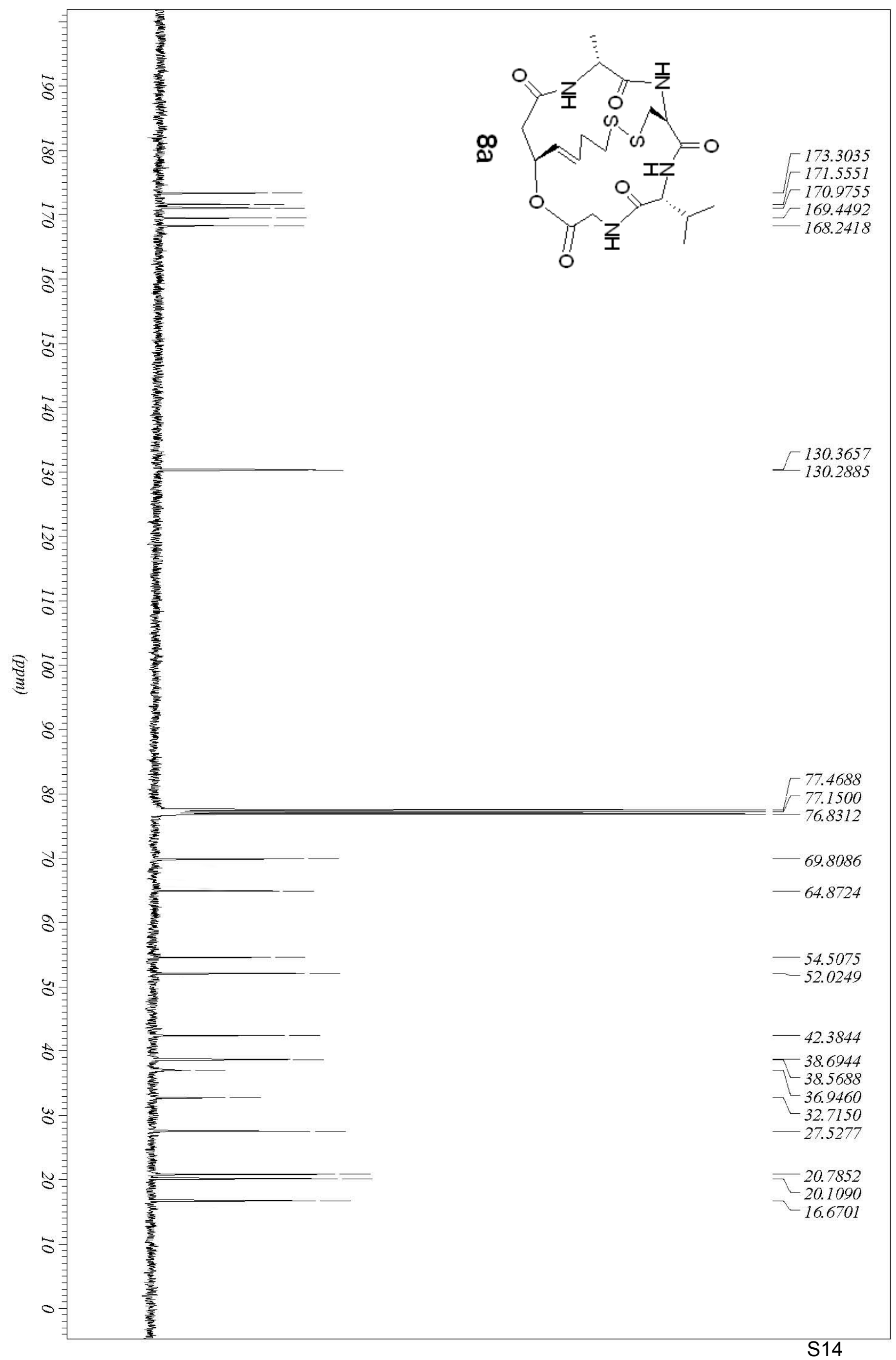




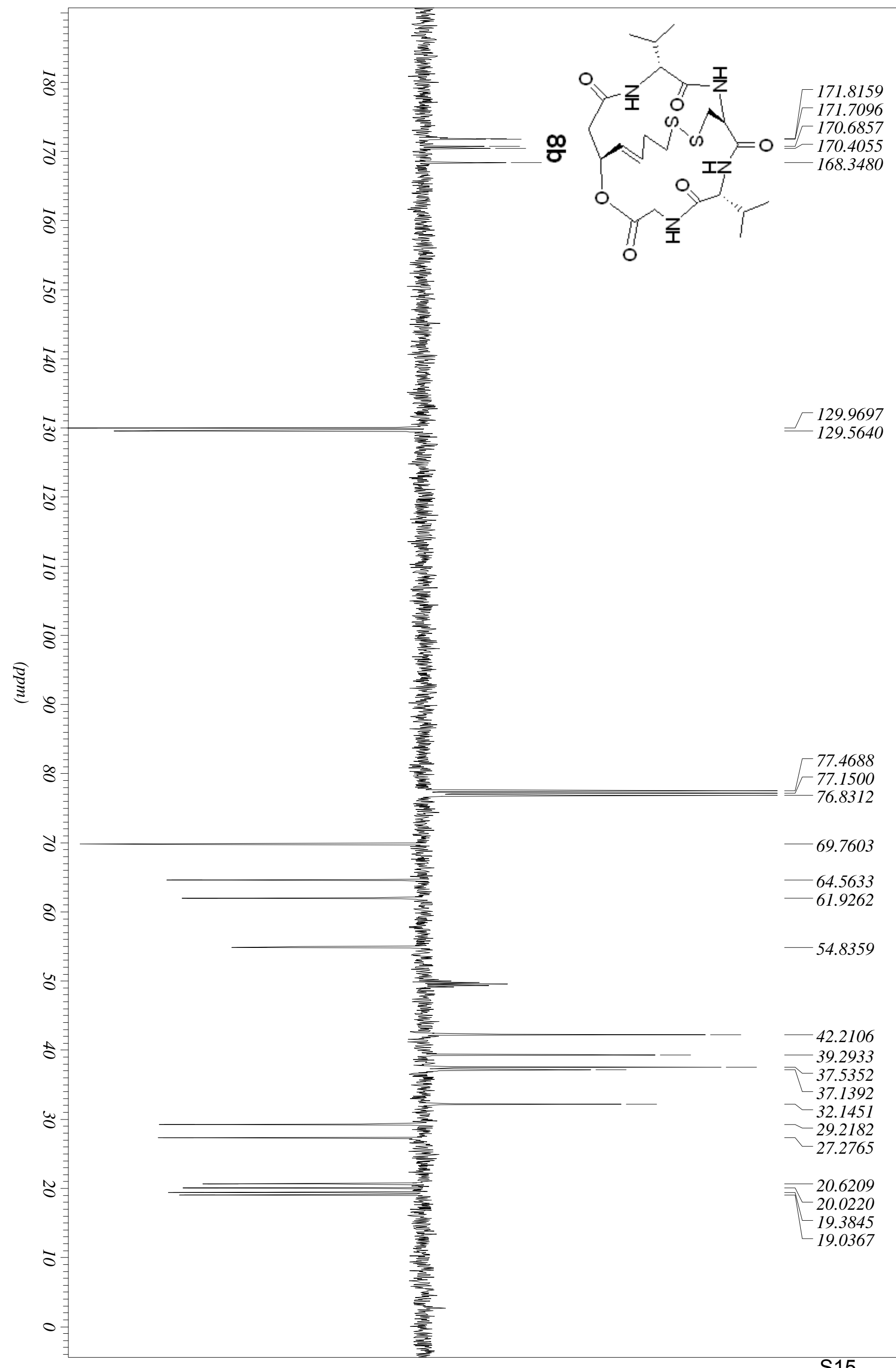




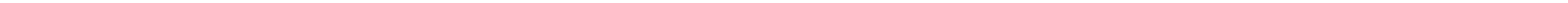




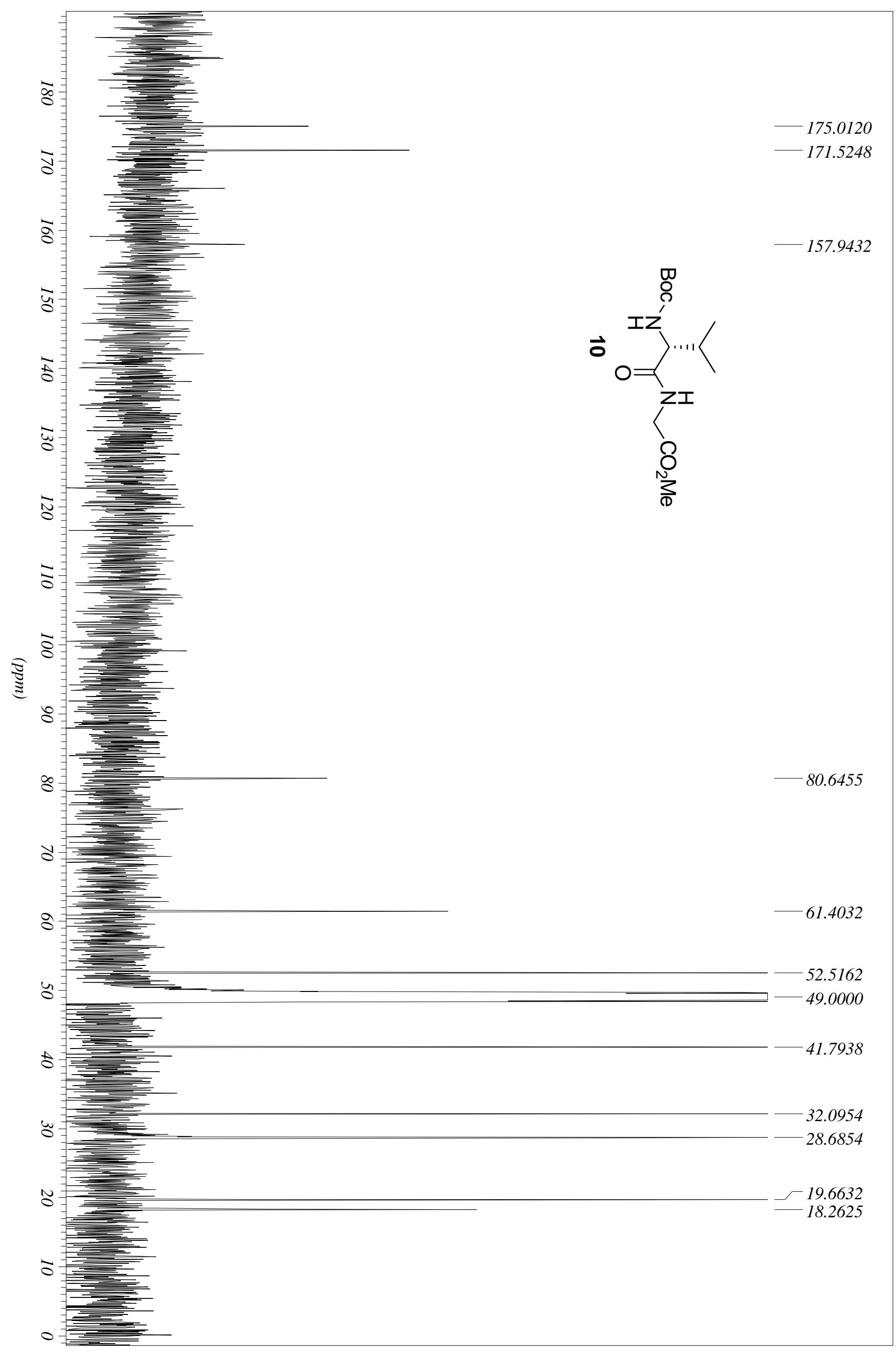




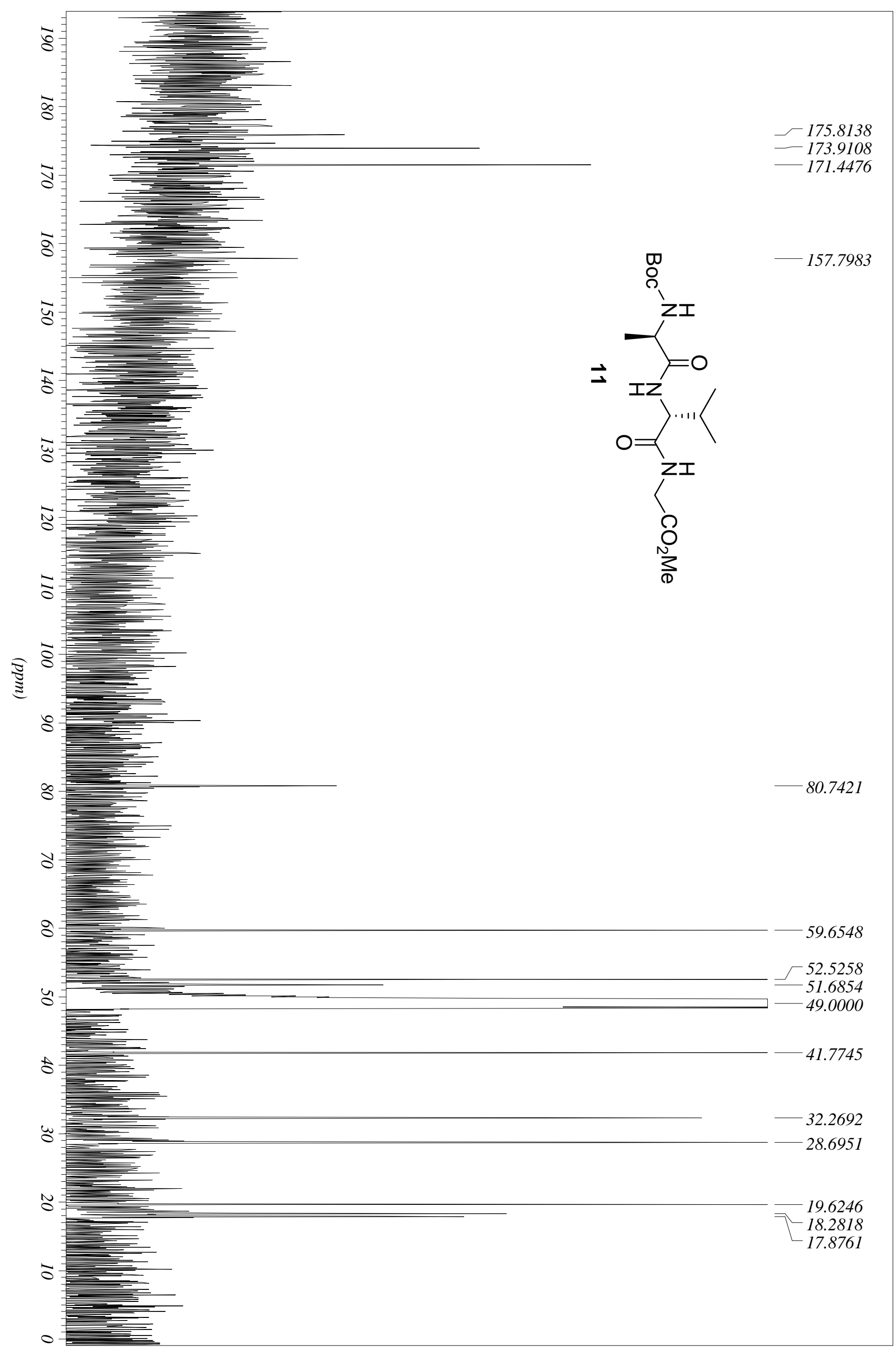




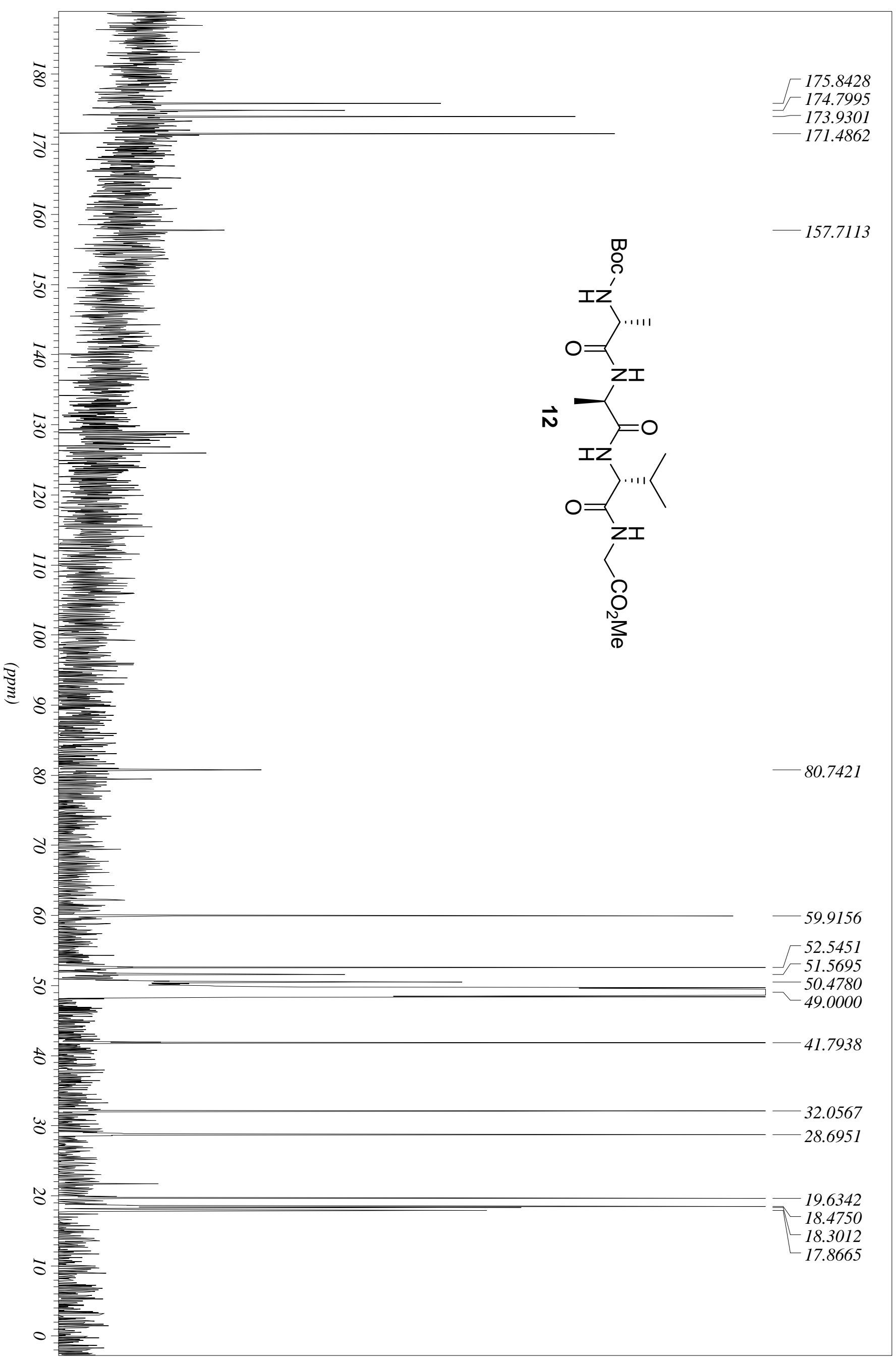

怘 


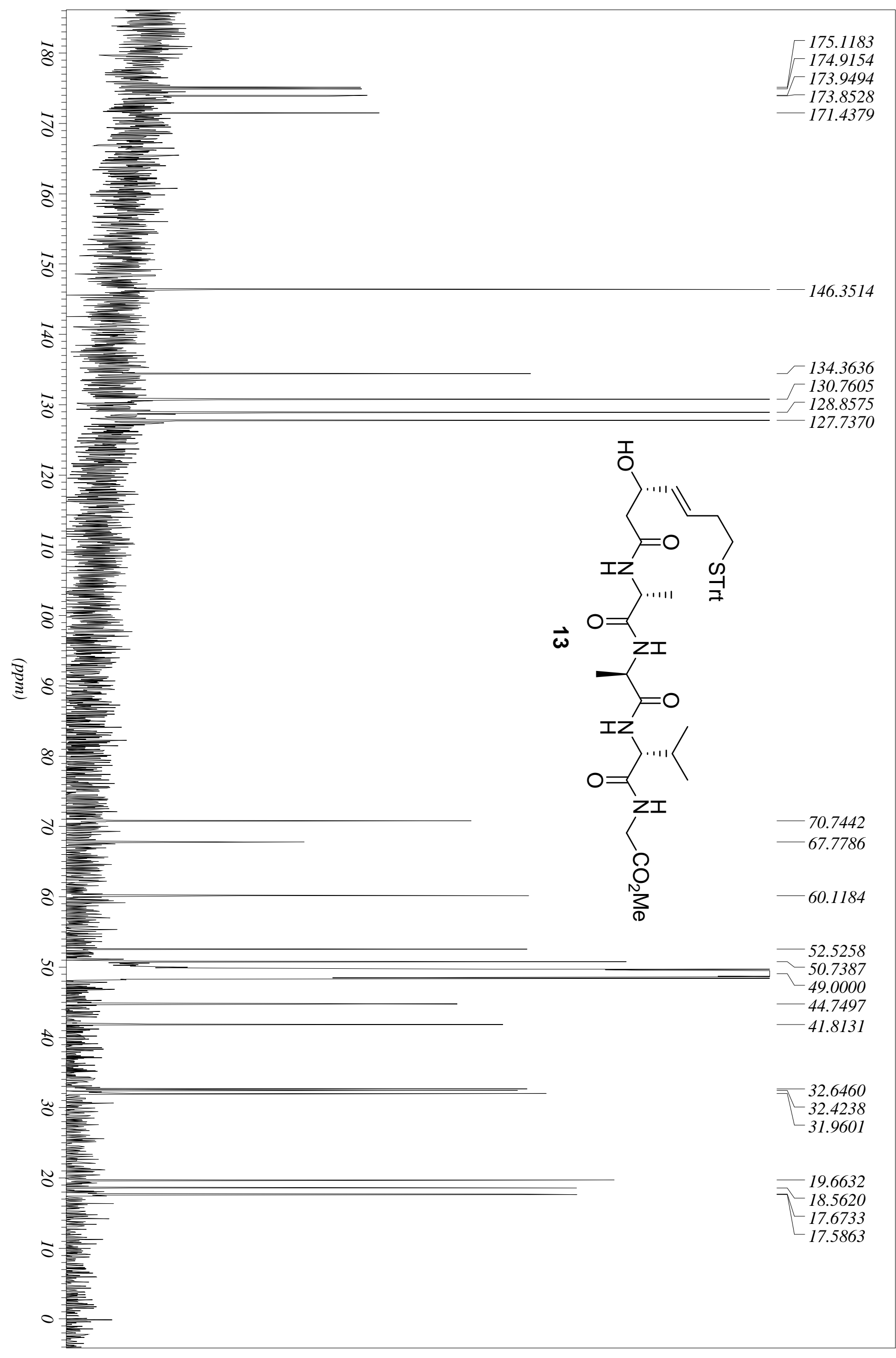




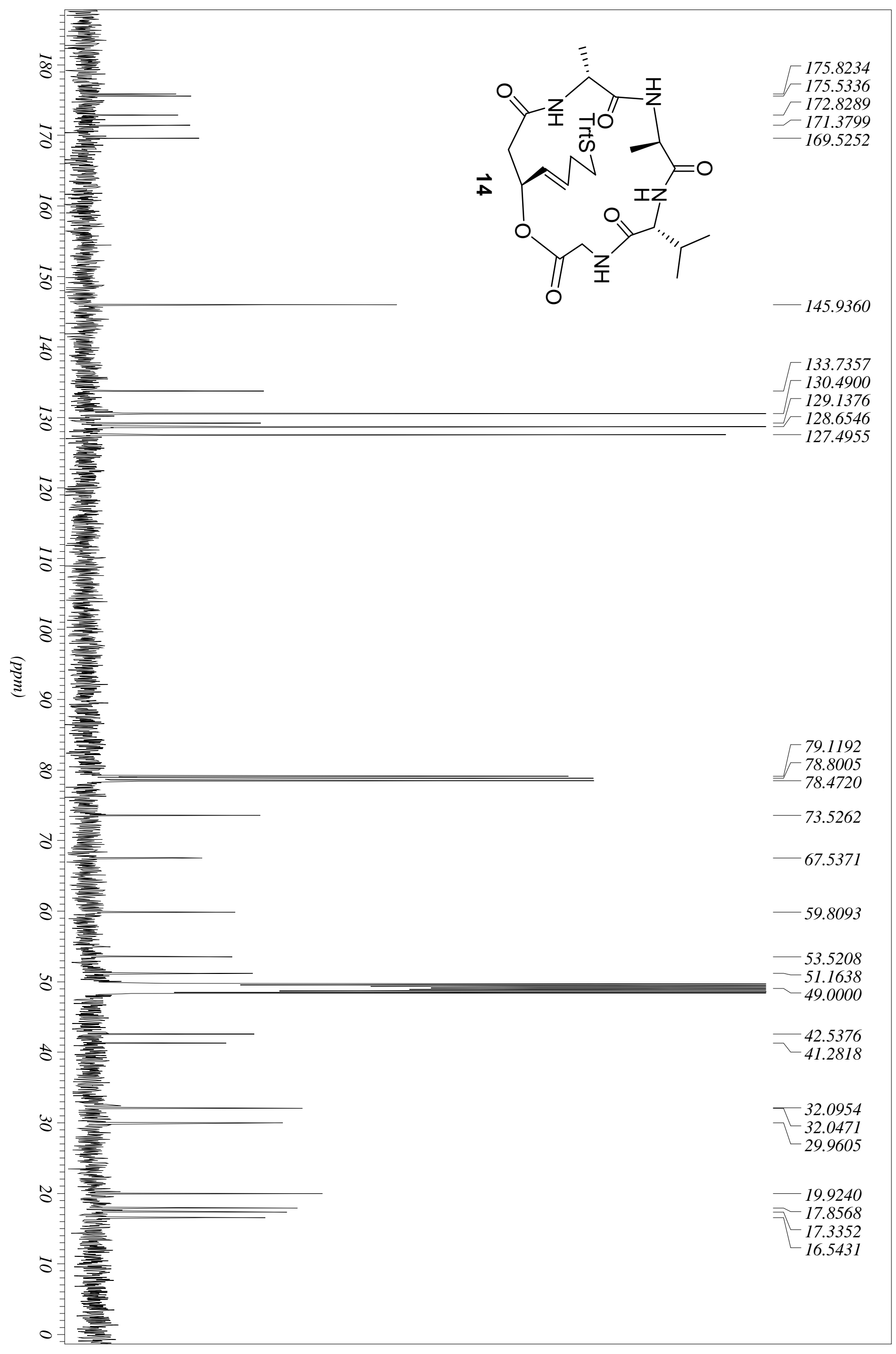




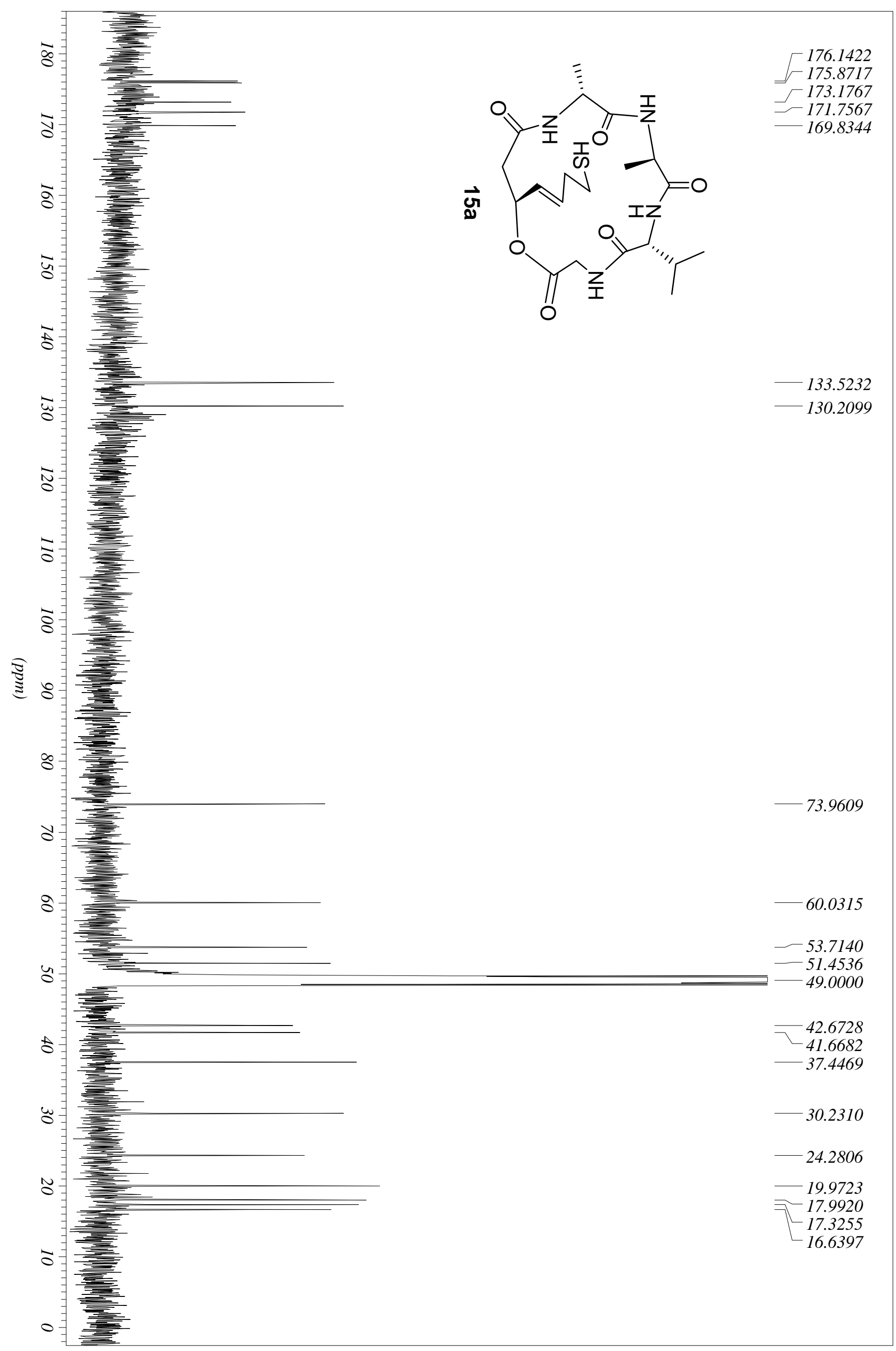




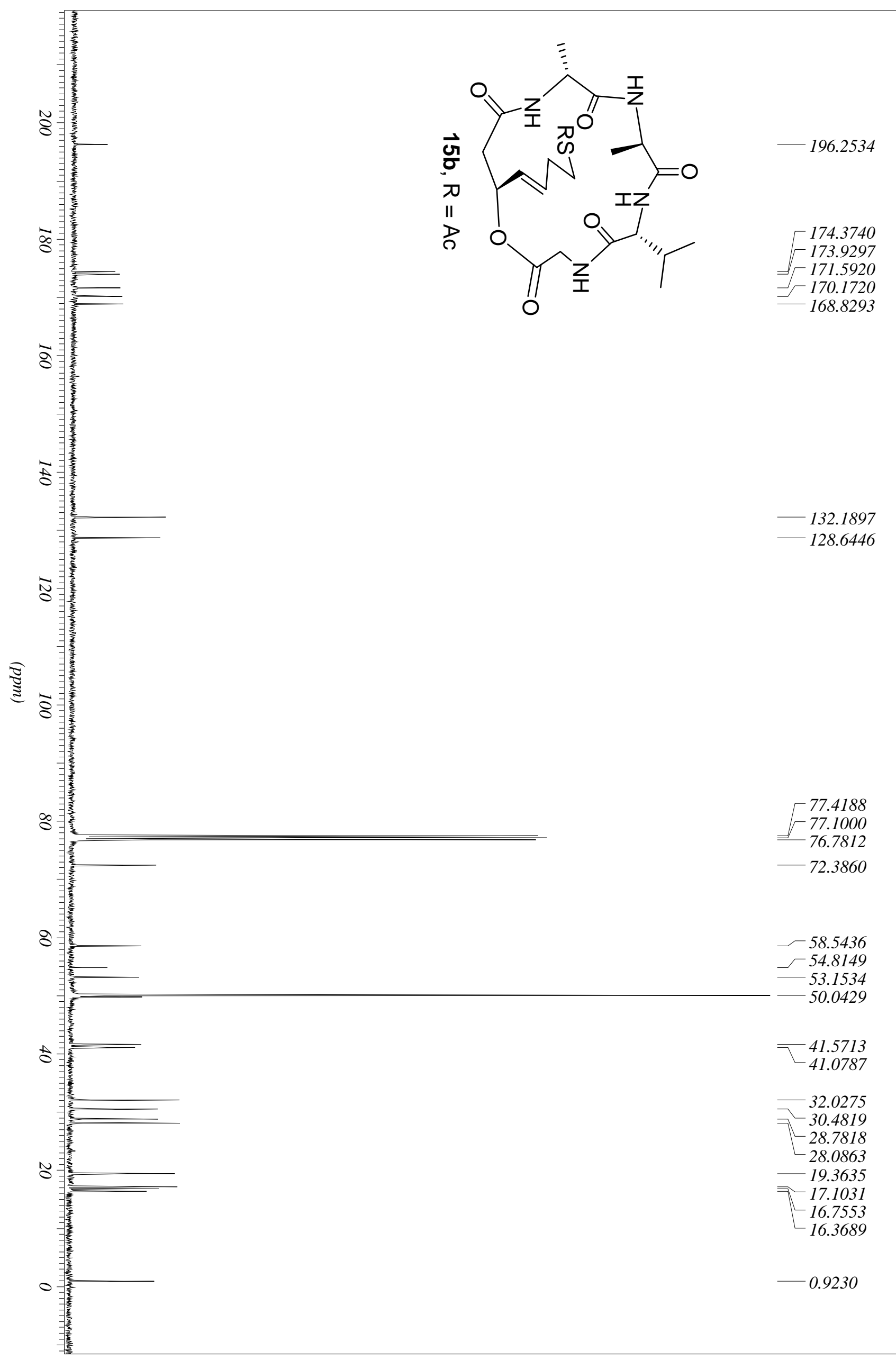




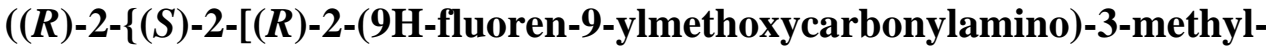

butyrylamino]-3-tritylsulfanyl-propionylamino\}-3-methyl-butyrylamino)-acetic acid

methyl ester (3b). To a stirred solution of 2 (836 mg, $1.11 \mathrm{mmol})$ in $\mathrm{CH}_{3} \mathrm{CN} / \mathrm{CH}_{2} \mathrm{Cl}_{2}$ $(1: 1,60 \mathrm{~mL})$ at $\mathrm{rt}$ was added $\mathrm{Et}_{2} \mathrm{NH}(3 \mathrm{~mL})$. After stirring for $3 \mathrm{~h}$ at $\mathrm{rt}$ the reaction mixture was diluted with heptane $(60 \mathrm{~mL})$ and concentrated to give the crude amine as a colourless oil. At $0{ }^{\circ} \mathrm{C}$ to a stirred solution of Fmoc-D-valine $(577 \mathrm{mg}, 1.7 \mathrm{mmol})$ in $\mathrm{CH}_{2} \mathrm{Cl}_{2}(40 \mathrm{~mL})$ was added EDAC $\cdot \mathrm{HCl}(326 \mathrm{mg}, 1.7 \mathrm{mmol}), \mathrm{HOBt}(230 \mathrm{mg}, 1.7 \mathrm{mmol})$ and $\mathrm{i}-\mathrm{Pr}_{2} \mathrm{NEt}(627 \mu \mathrm{l}, 3.6 \mathrm{mmol})$. After stirring for $5 \mathrm{~min}$ a solution of the crude amine in $\mathrm{CH}_{2} \mathrm{Cl}_{2}(20 \mathrm{~mL})$ was then added and the reaction mixture warmed to $\mathrm{rt}$ and stirred for 12 h. Whereupon the reaction was washed with water $(15 \mathrm{~mL}), 10 \% \mathrm{HCl}(15 \mathrm{~mL}), 5 \%$ $\mathrm{NaHCO}_{3}(15 \mathrm{~mL})$ and sat $\mathrm{NaCl}(15 \mathrm{~mL})$ solutions, dried $\left(\mathrm{Na}_{2} \mathrm{SO}_{4}\right)$, filtered, and the solvent removed to give an off white solid which was recrystallised from $\mathrm{CH}_{3} \mathrm{CN}$ to give 3b as a white solid (734 mg, $0.86 \mathrm{mmol}, 78 \%):{ }^{1} \mathrm{H}-\mathrm{NMR}\left(400 \mathrm{MHz}, \mathrm{CDCl}_{3}\right) \delta 7.74(\mathrm{~d}, J$ $=7.5 \mathrm{~Hz}, 2 \mathrm{H}), 7.53(\mathrm{t}, J=7.5 \mathrm{~Hz}, 2 \mathrm{H}), 7.42-7.32(\mathrm{~m}, 9 \mathrm{H}), 7.30-7.19(\mathrm{~m}, 9 \mathrm{H}), 7.16(\mathrm{t}, J=$ $7.0 \mathrm{~Hz}, 2 \mathrm{H}), 6.80(\mathrm{~d}, J=8.0 \mathrm{~Hz}, 1 \mathrm{H}), 6.57(\mathrm{~d}, J=7.0 \mathrm{~Hz}, 1 \mathrm{H}), 5.52(\mathrm{~d}, J=8.0 \mathrm{~Hz}, 1 \mathrm{H})$, $4.44(\mathrm{t}, J=8.0 \mathrm{~Hz}, 1 \mathrm{H}), 4.38(\mathrm{dd}, J=10.5,7.5 \mathrm{~Hz}, 1 \mathrm{H}), 4.25(\mathrm{dd}, J=10.5,7.0 \mathrm{~Hz}, 1 \mathrm{H})$, 4.17-3.95 (m, 3H), $3.87(\mathrm{dd}, J=18.1,5.5 \mathrm{~Hz}, 1 \mathrm{H}), 3.78(\mathrm{dd}, J=18.1,5.5 \mathrm{~Hz}, 1 \mathrm{H}), 3.63$ (s, 3H), $2.71(\mathrm{dd}, J=12.5,6.0 \mathrm{~Hz}, 1 \mathrm{H}), 2.53(\mathrm{dd}, J=12.5,6.0 \mathrm{~Hz}, 1 \mathrm{H}), 2.21$ (sept, $J=$ $6.4 \mathrm{~Hz}, 1 \mathrm{H}), 2.07-1.93(\mathrm{~m}, 1 \mathrm{H}), 0.93-0.83(\mathrm{~m}, 12 \mathrm{H}) ;{ }^{13} \mathrm{C} \mathrm{NMR}\left(100 \mathrm{MHz}, \mathrm{CDCl}_{3}\right) \delta$ $171.5,171.1,170.2$ x 2, 156.6, 144.4, 144.0, 143.8, 141.4, 129.6, 128.3, 127.9, 127.2, $127.1,125.2,120.1,67.3,67.2,60.3,58.5,52.5,52.3,47.3,41.0,33.8,31.5,30.5,19.2 \times$ 2, 18.0, 17.8; LRMS (ES+) m/z $1832\left(10 \%,[2 \mathrm{M}+\mathrm{Na}]^{+}\right), 877.5\left(100 \%,[\mathrm{M}+\mathrm{Na}]^{+}\right) ; \mathrm{HRMS}$ (ES+) $\mathrm{C}_{50} \mathrm{H}_{54} \mathrm{~N}_{4} \mathrm{O}_{7} \mathrm{~S}_{1} \mathrm{Na}$ Calcd. 877.3605, found 877.3607. 


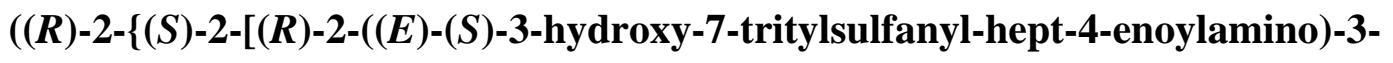
methylbutyrylamino]-3-tritylsulfanyl-propionylamino\}-3-methyl-butyrylamino)acetic acid methyl ester (5b). To a stirred solution of $3 \mathbf{b}(235 \mathrm{mg}, 0.28 \mathrm{mmol})$ in $\mathrm{CHCl}_{3} / \mathrm{CH}_{3} \mathrm{CN}(1: 1,14 \mathrm{~mL})$ at $\mathrm{rt}$ was added $\mathrm{Et}_{2} \mathrm{NH}(1 \mathrm{~mL})$. After stirring for $5 \mathrm{~h}$ at $\mathrm{rt}$ the reaction mixture was diluted with heptane $(10 \mathrm{~mL})$ and solvent removed to give the crude amine as a colourless oil. To a stirred solution of the crude amine in $\mathrm{CH}_{2} \mathrm{Cl}_{2}(10 \mathrm{~mL})$ was added a solution of $4(193 \mathrm{mg}, 0.34 \mathrm{mmol})$ in $\mathrm{CH}_{2} \mathrm{Cl}_{2}(5 \mathrm{~mL})$ and DMAP $(4 \mathrm{mg}, 0.034$ mmol) at $\mathrm{rt}$. After stirring at $\mathrm{rt}$ for 12 hours, the solvent was removed and the residue was purified by flash chromatography (eluent $\left.1-3 \% \mathrm{MeOH} / \mathrm{CH}_{2} \mathrm{Cl}_{2}\right)$ to give $5 \mathbf{b}(230 \mathrm{mg}$, 81\%) as a white solid: ${ }^{1} \mathrm{H}$ NMR $\left(400 \mathrm{MHz}, \mathrm{CDCl}_{3}\right) \delta$ 7.42-7.38 (m, 12H), 7.30-7.14 (m, 20H), 6.74 (br s, 1H), 6.39 (br s, 1H), 5.49 (dtd, $J=15.3,6.5,0.8 \mathrm{~Hz}, 1 \mathrm{H}), 5.36$ (dd, $J=$ 15.3, $6.3 \mathrm{~Hz}, 1 \mathrm{H}), 4.39-4.26(\mathrm{~m}, 3 \mathrm{H}), 4.16-4.06(\mathrm{~m}, 1 \mathrm{H}), 3.83(\mathrm{~d}, J=5.5 \mathrm{~Hz}, 2 \mathrm{H}), 3.65$ (s, 3H), 3.33 (br s, 1H), 2.60 (dd, $J=12.8,7.3 \mathrm{~Hz}, 1 \mathrm{H}), 2.54$ (dd, $J=12.8,6.8 \mathrm{~Hz}, 1 \mathrm{H})$, $2.37(\mathrm{dd}, J=14.0,3.0 \mathrm{~Hz}, 1 \mathrm{H}), 2.30-2.02(\mathrm{~m}, 7 \mathrm{H}), 0.90(\mathrm{~d}, J=7.0 \mathrm{~Hz}, 3 \mathrm{H}), 0.89(\mathrm{~d}, J=$ $7.0 \mathrm{~Hz}, 3 \mathrm{H}), 0.88(\mathrm{~d}, J=7.0 \mathrm{~Hz}, 3 \mathrm{H}), 0.85(\mathrm{~d}, J=7.0 \mathrm{~Hz}, 3 \mathrm{H}) ;{ }^{13} \mathrm{C}$ NMR $(100 \mathrm{MHz}$, $\left.\mathrm{CDCl}_{3}\right) \delta 172.1,171.4,171.2,170.5,170.3,145.0,144.3,132.6,130.2,129.7,129.5$, $128.3,128.0,127.1,126.8,69.8,67.1,66.8,59.0,58.9,52.5,52.3,43.9,41.0,33.7,31.5 \mathrm{x}$ 2, 30.4, 30.2, 19.5, 19.3, 17.9 x 2; LRMS (ES+) $\left.\mathrm{m} / \mathrm{z} 1056(100 \% \text {, [M+Na }]^{+}\right), 1051(50 \%$, $\left.\left[\mathrm{M}+\mathrm{NH}_{4}\right]^{+}\right)$.

\section{$(6 R, 9 S, 12 R, 16 S)-6,12-d i i s o p r o p y l-16-((E)-4-t r i t y l s u l f a n y l-b u t-1-e n y l)-9-$} tritylsulfanylmethyl-1-oxa-4,7,10,13-tetraaza-cyclohexadecane-2,5,8,11,14-pentaone (7b). At $0{ }^{\circ} \mathrm{C}$ to a stirred solution of methyl ester $5 \mathbf{b}(220 \mathrm{mg}, 0.21 \mathrm{mmol})$ in THF (12 $\mathrm{mL}$ ) was added a solution of $\mathrm{LiOH}(7.6 \mathrm{mg}, 0.32)$ in $\mathrm{H}_{2} \mathrm{O}(2 \mathrm{~mL})$. After $1 \mathrm{~h}$ the reaction 
was quenched by addition of $1 \mathrm{M} \mathrm{HCl}(6 \mathrm{~mL})$. $\mathrm{CHCl}_{3}(50 \mathrm{~mL})$ was added and the organic phase separated, extracting with $\mathrm{CHCl}_{3}(2 \times 15 \mathrm{~mL})$. The organic phase was washed with brine $(10 \mathrm{~mL})$, dried $\left(\mathrm{MgSO}_{4}\right)$, filtered, and concentrated in vacuo to give the crude acid 6b (217 $\mathrm{mg}$, quantative) as a white solid that was used immediately in the next step: (ES) $\mathrm{m} / \mathrm{z} 1017\left(100 \%,[\mathrm{M}-\mathrm{H}]^{-}\right)$.

To a stirred solution of MNBA (90 mg, $0.26 \mathrm{mmol})$ and DMAP (62 mg, $0.51 \mathrm{mmol})$ in $\mathrm{CH}_{2} \mathrm{Cl}_{2}(50 \mathrm{~mL})$ was added dropwise a solution of acid $6 \mathbf{b}(217 \mathrm{mg}, 0.21 \mathrm{mmol})$ in $\mathrm{CH}_{2} \mathrm{Cl}_{2} / \mathrm{THF}(15: 1,200 \mathrm{~mL})$ over $3 \mathrm{~h}\left(\mathrm{Nb}\right.$. dissolve acid in THF first then add $\left.\mathrm{CH}_{2} \mathrm{Cl}_{2}\right)$. After a further $14 \mathrm{~h}$ the reaction was quenched by the addition of $1 \mathrm{M} \mathrm{HCl}(40 \mathrm{~mL})$. The organic phase was separated (extracting with $\mathrm{CH}_{2} \mathrm{Cl}_{2}$ ) and washed sequentially with $\mathrm{NaHCO}_{3}(30 \mathrm{~mL})$ and brine $(20 \mathrm{~mL})$. The combined organic phase was dried $\left(\mathrm{MgSO}_{4}\right)$, filtered, and concentrated in vacuo to give a yellow oil. Purification by column chromatography on silica gel $\left(30-70 \% \mathrm{EtOAc} / \mathrm{CH}_{2} \mathrm{Cl}_{2}\right)$ gave $7 \mathbf{b}(130 \mathrm{mg}, 0.13 \mathrm{mmol}$, 62\%) as a white solid: ${ }^{1} \mathrm{H}-\mathrm{NMR}\left(400 \mathrm{MHz}, \mathrm{CDCl}_{3}\right) \delta 7.88$ (br s, $\left.2 \mathrm{H}\right), 7.42-7.34(\mathrm{~m}$, $12 \mathrm{H}), 7.29-7.14(\mathrm{~m}, 19 \mathrm{H}), 6.20(\mathrm{br} \mathrm{d}, J=7.0 \mathrm{~Hz}, 1 \mathrm{H}), 5.62-5.50(\mathrm{~m}, 2 \mathrm{H}), 5.31(\mathrm{dd}, J=$ 15.3, $6.4 \mathrm{~Hz}, 1 \mathrm{H}), 4.36(\mathrm{dd}, J=17.3,8.3 \mathrm{~Hz}, 1 \mathrm{H}), 4.24(\mathrm{dd}, J=8.5,4.5 \mathrm{~Hz}, 1 \mathrm{H}), 4.11(\mathrm{t}$, $J=7.3 \mathrm{~Hz}, 1 \mathrm{H}), 3.65-3.56(\mathrm{~m}, 1 \mathrm{H}), 3.42(\mathrm{~d}, J=14.5 \mathrm{~Hz}, 1 \mathrm{H}), 2.99(\mathrm{t}, J=10.8 \mathrm{~Hz}, 1 \mathrm{H})$, $2.64(\mathrm{dd}, J=12.0,6.3 \mathrm{~Hz}, 1 \mathrm{H}), 2.50(\mathrm{dd}, J=15.1,2.5 \mathrm{~Hz}, 1 \mathrm{H}), 2.35(\mathrm{dd}, J=14.8,9.8$ $\mathrm{Hz}, 1 \mathrm{H}), 2.17(\mathrm{t}, J=7.5 \mathrm{~Hz}, 2 \mathrm{H}), 2.06-1.86(\mathrm{~m}, 3 \mathrm{H}), 1.84-1.72(\mathrm{~m}, 1 \mathrm{H}), 0.91(\mathrm{~d}, J=6.8$ $\mathrm{Hz}, 3 \mathrm{H}), 0.88(\mathrm{~d}, J=6.3 \mathrm{~Hz}, 6 \mathrm{H}), 0.83(\mathrm{~d}, J=6.8 \mathrm{~Hz}, 3 \mathrm{H}) ;{ }^{13} \mathrm{C}-\mathrm{NMR}\left(100 \mathrm{MHz}, \mathrm{CDCl}_{3}\right)$ $\delta 173.8,172.2,171.0,169.5,168.9,145.0,144.4,132.7,129.7,128.2,128.1,128.0$ $127.0,126.8,72.2,67.3,66.8,58.8,58.7,58.4,42.1,41.9,32.0,31.5,31.3,31.2,29.4$, 19.6, 19.4 18.5, 17.0; LRMS (ES+) m/z $1023\left(100 \%,[\mathrm{M}+\mathrm{Na}]^{+}\right), 1018\left(60 \%,\left[\mathrm{M}+\mathrm{NH}_{4}\right]^{+}\right)$. 


\section{(E)-(1S,7R,10S,21R)-7,21-diisopropyl-2-oxa-12,13-dithia-5,8,20,23-tetraaza-}

bicyclo[8.7.6]tricos-16-ene-3,6,9,19,22-pentaone (8b). To a vigorously stirred solution of $\mathrm{I}_{2}(305 \mathrm{mg}, 1.2 \mathrm{mmol})$ in $\mathrm{CH}_{2} \mathrm{Cl}_{2} / \mathrm{MeOH}(9: 1,280 \mathrm{~mL})$ was added dropwise a solution of bis-trityl 7b (120 mg, $0.12 \mathrm{mmol})$ over 30 minutes. After a further 30 min the reaction was quenched by the addition of sodium thiosulfate $(0.05 \mathrm{M}, 100 \mathrm{~mL})$ followed by brine $(10 \mathrm{~mL})$. The organic phase was separated and the aqueous phase extracted with EtOAc ( $3 \times 25 \mathrm{~mL})$. The combined organic phase was dried $\left(\mathrm{MgSO}_{4}\right)$, filtered, and concentrated in vacuo to give a white solid. Purification by column chromatography on silica gel (14\% $\left.\mathrm{MeOH} / \mathrm{CH}_{2} \mathrm{Cl}_{2}\right)$ gave bicyclic depsipeptide $8 \mathbf{b}(60 \mathrm{mg}, 0.12 \mathrm{mmol}, 97 \%)$ as a white solid: $\mathrm{mp}=$ dec. $>235{ }^{\circ} \mathrm{C} ;[\alpha]^{25}-105.7\left(1: 1 \mathrm{MeOH} / \mathrm{CHCl}_{3}, c\right.$ 0.15); ${ }^{1} \mathrm{H}-\mathrm{NMR}(400$ $\left.\mathrm{MHz}, \mathrm{CD}_{3} \mathrm{OD}\right) \delta 5.76-5.63(\mathrm{~m}, 3 \mathrm{H}), 4.52(\mathrm{dd}, J=11.3,4.7 \mathrm{~Hz}, 1 \mathrm{H}), 3.96(\mathrm{~d}, J=5.1 \mathrm{~Hz}$ 1H), $3.74(\mathrm{~d}, J=17.5 \mathrm{~Hz}, 1 \mathrm{H}), 3.38(\mathrm{~d}, J=10.9 \mathrm{~Hz}, 1 \mathrm{H}), 3.19-3.11(\mathrm{~m}, 2 \mathrm{H}), 3.09-2.96$ (m, 3H), $2.90(\mathrm{dd}, J=13.6,2.5 \mathrm{~Hz}, 1 \mathrm{H}), 2.71-2.62(\mathrm{~m}, 2 \mathrm{H}), 2.58-2.44(\mathrm{~m}, 1 \mathrm{H}), 2.31-2.18$ $(\mathrm{m}, 1 \mathrm{H}), 1.11(\mathrm{~d}, J=7.0 \mathrm{~Hz}, 3 \mathrm{H}), 1.09(\mathrm{~d}, J=7.0 \mathrm{~Hz}, 3 \mathrm{H}), 1.01(\mathrm{~d}, J=6.6 \mathrm{~Hz}, 3 \mathrm{H}), 0.91$ $(\mathrm{d}, J=6.6 \mathrm{~Hz}, 3 \mathrm{H}) ;{ }^{13} \mathrm{C}-\mathrm{NMR}\left(100 \mathrm{MHz}, 9: 1 \mathrm{CDCl}_{3} / \mathrm{CD}_{3} \mathrm{OD}\right) \delta$ 171.8, 171.7, 170.7, $170.4,168.3,130.0,129.6,69.8,64.6,61.9,54.8,42.2,39.3,37.5,37.1,32.1,29.2,27.3$, 20.6, 20.0, 19.4, 19.0; LRMS (ES+) m/z $537\left(100 \%,[\mathrm{M}+\mathrm{Na}]^{+}\right), 515\left(90 \%,[\mathrm{M}+\mathrm{H}]^{+}\right)$; HRMS (ES+) $\mathrm{C}_{22} \mathrm{H}_{34} \mathrm{~N}_{4} \mathrm{O}_{6} \mathrm{~S}_{2} \mathrm{Na}$ Calcd. 537.1812, found 537.1805.

\section{\{(R)-2-[((E)-(4S,7S,11S)-11-Hydroxy-7-methyl-6,9-dioxo-1,2-dithia-5,8-diaza-} cyclopentadec-12-ene-4-carbonyl)-amino]-3-methyl-butyrylamino\}-acetic acid methyl ester (9). To a vigorously stirring solution of $I_{2}(51 \mathrm{mg}, 0.2 \mathrm{mmol})$ in $\mathrm{CH}_{2} \mathrm{Cl}_{2} / \mathrm{MeOH}(9: 1,65 \mathrm{~mL})$ was added the protected dithiol $5 \mathrm{a}(20 \mathrm{mg}, 0.02 \mathrm{mmol})$ in $\mathrm{CH}_{2} \mathrm{Cl}_{2} / \mathrm{MeOH}(9: 1,10 \mathrm{~mL})$ dropwise over 30 minutes. After stirring for a further 30 
minutes, $0.1 \mathrm{M}$ sodium thiosulfate $(40 \mathrm{~mL})$ and sat. $\mathrm{NaCl}(20 \mathrm{~mL})$ were added, extracting with $\mathrm{CH}_{2} \mathrm{Cl}_{2}(3 \times 30 \mathrm{~mL})$. The combined organic extract was dried $\left(\mathrm{MgSO}_{4}\right)$, filtered, and solvent removed. The residue was purified by flash chromatography (eluent $3-10 \%$ $\left.\mathrm{MeOH} / \mathrm{CHCl}_{3}\right)$ to give 9 (2 mg, $\left.0.004 \mathrm{mmol}, 20 \%\right)$ as a white solid: ${ }^{1} \mathrm{H} \mathrm{NMR}(400 \mathrm{MHz}$, $\left.\mathrm{CD}_{3} \mathrm{OD}\right) \delta 5.74(\mathrm{dtd}, J=15.6,6.5,1.0 \mathrm{~Hz}, 1 \mathrm{H}), 5.55(\mathrm{ddt}, J=15.6,6.0,1.0 \mathrm{~Hz}, 1 \mathrm{H}), 4.73$ (dd, $J=9.0,4.5 \mathrm{~Hz}, 1 \mathrm{H}), 4.45(\mathrm{q}, J=7.0 \mathrm{~Hz}, 1 \mathrm{H}), 4.41-4.35(\mathrm{~m}, 1 \mathrm{H}), 4.24(\mathrm{~d}, J=7.0 \mathrm{~Hz}$, $1 \mathrm{H}), 3.88(\mathrm{~d}, J=7.6 \mathrm{~Hz}, 1 \mathrm{H}), 3.71(\mathrm{~s}, 3 \mathrm{H}), 3.23(\mathrm{dd}, J=16.5,4.5 \mathrm{~Hz}, 1 \mathrm{H}), 2.91-2.82(\mathrm{~m}$, 2H), 2.77-2.66 (m, 2H), 2.44-2.33 (m, 3H), 2.17-2.08 (m, 1H), 1.32 (d, J=7.0 Hz, 3H), $0.98(\mathrm{t}, J=6.8 \mathrm{~Hz}, 6 \mathrm{H}) ;$ LRMS $(\mathrm{ES}+) \mathrm{m} / \mathrm{z} 541\left(100 \%,[\mathrm{M}+\mathrm{Na}]^{+}\right) ;$HRMS (ES+) $\mathrm{C}_{21} \mathrm{H}_{34} \mathrm{~N}_{4} \mathrm{O}_{7} \mathrm{~S}_{2} \mathrm{Na}$ Calcd. 541.1761, found 541.1766.

((R)-2-tert-Butoxycarbonylamino-3-methyl-butyrylamino)-acetic acid methyl ester

10: To a stirred solution of Boc-D-valine $(1.00 \mathrm{~g}, 4.60 \mathrm{mmol})$ in $\mathrm{CH}_{2} \mathrm{Cl}_{2}(20 \mathrm{~mL})$ was added $\mathrm{EDAC} \cdot \mathrm{HCl}(1.06 \mathrm{~g}, 5.52 \mathrm{mmol}), \mathrm{HOBt} \cdot \mathrm{H}_{2} \mathrm{O}(752 \mathrm{mg}, 5.52 \mathrm{mmol})$ and i-Pr $2 \mathrm{NEt}$ $(2.81 \mathrm{~mL}, 16.1 \mathrm{mmol})$ at $0{ }^{\circ} \mathrm{C}$ under inert atmosphere. Glycine methyl ester. $\mathrm{HCl}(636 \mathrm{mg}$, $5.06 \mathrm{mmol}$ ) was added and the reaction mixture stirred for $3 \mathrm{~h}$ at $\mathrm{rt}$. The solution was washed and separated sequentially with distilled water $(20 \mathrm{~mL})$, saturated $\mathrm{NH}_{4} \mathrm{Cl}$ solution $(20 \mathrm{~mL})$ and saturated brine solution $(20 \mathrm{~mL})$, then dehydrated with $\mathrm{Na}_{2} \mathrm{SO}_{4}$. The solvent was removed and the residue purified with flash chromatography (EtOAc/hexane 1:1) to generate a white solid 10 (1.05 g, 79\% yield): IR $v_{\max } 3312,2956,1748,1685,1653$, $1522,1208,1165 \mathrm{~cm}^{-1} ;{ }^{1} \mathrm{H}$ NMR $\left(300 \mathrm{MHz}, \mathrm{CDCl}_{3}\right) \delta 6.48$ (brs, $\left.1 \mathrm{H}\right), 5.03$ (brs, $\left.1 \mathrm{H}\right)$, $4.07(\mathrm{~d}, J=2.1 \mathrm{~Hz}, 1 \mathrm{H}), 4.05(\mathrm{~d}, J=1.8 \mathrm{~Hz}, 1 \mathrm{H}), 4.00(\mathrm{dd}, J=8.4,6.2 \mathrm{~Hz}, 1 \mathrm{H}), 3.76(\mathrm{~s}$, $3 \mathrm{H}), 2.21(\mathrm{~m}, 1 \mathrm{H}), 1.46$ (s, $9 \mathrm{H}), 0.99(\mathrm{~d}, 3 \mathrm{H}, J=6.9 \mathrm{~Hz}, 3 \mathrm{H}), 0.94(\mathrm{~d}, J=6.9 \mathrm{~Hz}, 3$ $\mathrm{H}) ;{ }^{13} \mathrm{C} \mathrm{NMR}\left(100 \mathrm{MHz}, \mathrm{CDCl}_{3}\right) \delta 175.0,171.5,157.9,80.6,61.4,52.5,41.8,32.1,28.7$, 
19.7, 18.3; LRMS (ES+) m/z $\left.311.3(100 \% \text {, [M+Na] }]^{+}\right)$, HRMS (ES+) $\mathrm{C}_{13} \mathrm{H}_{24} \mathrm{~N}_{2} \mathrm{O}_{5} \mathrm{Na}$ Calcd. 311.1577, found 311.1578.

\section{[(R)-2-((R)-2-tert-Butoxycarbonylamino-propionylamino)-3-methyl-}

butyrylamino]-acetic acid methyl ester 11: At rt to a stirred solution of $\mathbf{1 0}$ (1.038 g, $3.60 \mathrm{mmol})$ in $\mathrm{CH}_{2} \mathrm{Cl}_{2}(20 \mathrm{~mL})$ was added TFA $(4.00 \mathrm{~mL}, 54 \mathrm{mmol})$. After $1.5 \mathrm{~h}$ the solution was diluted with hexane $(20 \mathrm{ml})$ and concentrated in vacuo, this was then repeated with toluene $(20 \mathrm{~mL})$ to give the deprotected amine as an oil. To a solution BocD-alanine $(0.749 \mathrm{mg}, 3.96 \mathrm{mmol})$ in $\mathrm{CH}_{2} \mathrm{Cl}_{2}(20 \mathrm{~mL})$ was added $\mathrm{EDAC} \cdot \mathrm{HCl}(827 \mathrm{mg}$, $4.32 \mathrm{mmol}), \mathrm{HOBt} . \mathrm{H}_{2} \mathrm{O}(588 \mathrm{mg}, 4.32 \mathrm{mmol})$, i- $\operatorname{Pr}_{2} \mathrm{NEt}(3.13 \mathrm{~mL}, 18 \mathrm{mmol})$ at $0{ }^{\circ} \mathrm{C}$. After stirring for 5 minutes a solution of the deprotected amine in $\mathrm{CH}_{2} \mathrm{Cl}_{2}(20 \mathrm{~mL})$ was then added and the reaction mixture warmed to $\mathrm{rt}$ and stirred for $3 \mathrm{~h}$. The solution was diluted with $\mathrm{CH}_{2} \mathrm{Cl}_{2}(20 \mathrm{ml})$, washed and separated sequentially with saturated $\mathrm{NH}_{4} \mathrm{Cl}$ solution $(20 \mathrm{~mL})$, saturated $\mathrm{NaHCO}_{3}$ solution $(20 \mathrm{~mL})$, saturated brine solution $(20 \mathrm{~mL})$ and dried with $\mathrm{Na}_{2} \mathrm{SO}_{4}$. The solvent was removed and the residue was purified by flash chromatography (eluent 100\% EtOAc) to generate a white solid 11 (674 mg, 52\% yield): IR $v_{\max } 3289,2965,1753,1636,1672,1516,1208 \mathrm{~cm}^{-1} ;{ }^{1} \mathrm{H} \mathrm{NMR}\left(300 \mathrm{MHz}, \mathrm{CDCl}_{3}\right)$

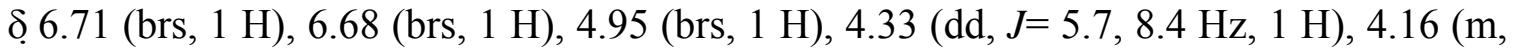
$1 \mathrm{H}), 4.03$ (m, $2 \mathrm{H}), 3.75$ (s, $3 \mathrm{H}), 2.27-2.34$ (m, $1 \mathrm{H}), 1.45$ (s, $9 \mathrm{H}), 1.39$ (d, J = 6.9 Hz, 3 $\mathrm{H}), 0.97(\mathrm{t}, J=6.9 \mathrm{~Hz}, 6 \mathrm{H})_{\mathrm{i}}{ }^{13} \mathrm{C} \mathrm{NMR}\left(100 \mathrm{MHz}, \mathrm{CDCl}_{3}\right) \delta 175.8,173.9,171.4,157.8$, 80.7, 59.7, 52.5, 51.7, 41.8, 32.3, 28.7, 19.6, 18.3, 17.9; LRMS (ES $\left.{ }^{+}\right) \mathrm{m} / \mathrm{z} 382.3(100 \%$, $[\mathrm{M}+\mathrm{Na}]^{+}$); HRMS (ES+) $\mathrm{C}_{16} \mathrm{H}_{29} \mathrm{~N}_{3} \mathrm{O}_{6} \mathrm{Na}$ Calcd. 382.1949, found 382.1948.

$\{(R)-2-[(R)-2-((R)-2$-tert-Butoxycarbonylamino-propionylamino)-

propionylamino]-3-methyl-butyrylamino\}-acetic acid methyl ester 12: At rt to a 
stirred solution of $11(667 \mathrm{mg}, 1.85 \mathrm{mmol})$ in $\mathrm{CH}_{2} \mathrm{Cl}_{2}(10.3 \mathrm{~mL})$ was added TFA (2.07 $\mathrm{mL}, 27.8 \mathrm{mmol})$. After $1.5 \mathrm{~h}$ the solution was diluted with hexane $(20 \mathrm{ml})$ and concentrated in vacuo, this was then repeated with toluene $(20 \mathrm{~mL})$ to give the deprotected amine as an oil. To a solution Boc-D-alanine (386 mg, $2.04 \mathrm{mmol}$ ) in $\mathrm{CH}_{2} \mathrm{Cl}_{2}$ $(15 \mathrm{ml})$ was added $\mathrm{EDAC} \cdot \mathrm{HCl}(426 \mathrm{mg}, 2.22 \mathrm{mmol}), \mathrm{HOBt} . \mathrm{H}_{2} \mathrm{O}(303 \mathrm{mg}, 2.22 \mathrm{mmol})$ and i- $\operatorname{Pr}_{2} \mathrm{NEt}(0.48 \mathrm{~mL}, 2.78 \mathrm{mmol})$ at $0{ }^{\circ} \mathrm{C}$. After stirring for 5 minutes a solution of the deprotected amine in $\mathrm{CH}_{2} \mathrm{Cl}_{2}(20 \mathrm{~mL})$ was then added and the reaction mixture warmed to $\mathrm{rt}$ and stirred for $3 \mathrm{~h}$. The solution was diluted with $\mathrm{CH}_{2} \mathrm{Cl}_{2}$ (15ml), washed and separated sequentially with saturated $\mathrm{NH}_{4} \mathrm{Cl}$ solution $(15 \mathrm{~mL})$, saturated $\mathrm{NaHCO}_{3}$ solution $(15 \mathrm{~mL})$, saturated brine solution $(15 \mathrm{~mL})$ and dried with $\mathrm{Na}_{2} \mathrm{SO}_{4}$. The solvent was removed and the residue was purified by flash chromatography (eluent $5-10 \%$ $\mathrm{MeOH} / \mathrm{EtOAc}$ ) to generate a white solid 12 (635 mg, 80\% yield): IR $v_{\max }$ 3276, 2971, 1753, 1666, 1630, 1510, 1161, $1051 \mathrm{~cm}^{-1} ;{ }^{1} \mathrm{H}$ NMR (400 MHz, $\left.\mathrm{CD}_{3} \mathrm{OD}\right) \delta .933$ (brs, 1 H), 4.39-4.40 (m, $1 \mathrm{H}), 4.22(\mathrm{~d}, J=7.1 \mathrm{~Hz}, 1 \mathrm{H}), 4.06-4.08(\mathrm{~m}, 1 \mathrm{H}), 4.00(\mathrm{~d}, J=17.6$ Hz, $1 \mathrm{H}), 3.90(\mathrm{~d}, J=17.6 \mathrm{~Hz}, 1 \mathrm{H}), 3.71(\mathrm{~s}, 3 \mathrm{H}), 2.08-2.16(\mathrm{~m}, 1 \mathrm{H}), 1.44(\mathrm{~s}, 9 \mathrm{H}), 1.36$ $(\mathrm{d}, J=7.5 \mathrm{~Hz}, 3 \mathrm{H}), 1.31(\mathrm{~d}, J=7.5 \mathrm{~Hz}, 3 \mathrm{H}), 0.97(\mathrm{t}, J=6.5 \mathrm{~Hz}, 6 \mathrm{H}) ;{ }^{13} \mathrm{C}$ NMR $(100$ $\left.\mathrm{MHz}, \mathrm{CD}_{3} \mathrm{OD}\right) \delta 175.8,174.8,173.9,171.5,157.7,80.7,59.9,52.5,51.6,50.5,41.8$, 32.1, 28.7, 19.6, 18.5, 18.3, 17.9; LRMS (ES+) $\mathrm{m} / \mathrm{z} 453.3\left(100 \%,[\mathrm{M}+\mathrm{Na}]^{+}\right)$; HRMS (ES+) $\mathrm{C}_{19} \mathrm{H}_{34} \mathrm{~N}_{4} \mathrm{O}_{7} \mathrm{Na}$ Calcd. 453.2320, found 453.2327.

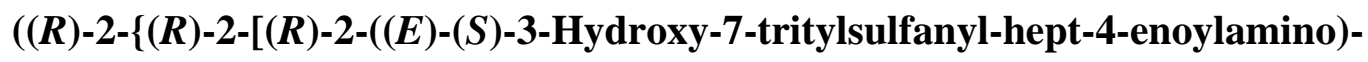
propionylamino]-propionylamino\}-3-methyl-butyrylamino)-acetic acid methyl ester

13: At $\mathrm{rt}$ to a stirred solution of $12(450 \mathrm{mg}, 1.04 \mathrm{mmol})$ in $\mathrm{CH}_{2} \mathrm{Cl}_{2}(20 \mathrm{~mL})$ was added TFA $(4.0 \mathrm{~mL}, 54 \mathrm{mmol})$. After $1.5 \mathrm{~h}$ the solution was diluted with hexane $(20 \mathrm{ml})$ and 
concentrated in vacuo, this was then repeated with toluene $(20 \mathrm{~mL})$ to give the deprotected amine as a solid. At $0{ }^{\circ} \mathrm{C}$ to a solution of the deprotected amine in $\mathrm{CH}_{2} \mathrm{Cl}_{2}$ (20 mL) was added i-Pr $2 \mathrm{NEt}(0.24 \mathrm{~mL}, 1.4 \mathrm{mmol})$. After $5 \mathrm{~min} 4(639 \mathrm{mg}, 1.14 \mathrm{mmol})$ and DMAP (15 mg, $0.13 \mathrm{mmol}$ ) were added before allowing the reaction mixture to warm to rt and stir for a further $8 \mathrm{~h}$. The solvent was removed and the residue purified by flash chromatography (eluent $\left.5 \% \mathrm{MeOH} / \mathrm{CH}_{2} \mathrm{Cl}_{2}\right)$ to give a white solid $13(517 \mathrm{mg}, 68 \%$ yield): IR $v_{\max } 3277,2958,1622,1532,694 \mathrm{~cm}^{-1} ;{ }^{1} \mathrm{H}$ NMR (400 MHz, $\left.\mathrm{CD}_{3} \mathrm{OD}\right) \delta .7 .21-$ 7.39 (m, $15 \mathrm{H}), 5.54$ (td, $J=6.5,15.1 \mathrm{~Hz}, 1 \mathrm{H}), 5.41(\mathrm{dd}, J=6.5,15.6 \mathrm{~Hz}, 1 \mathrm{H}), 4.30-$ $4.41(\mathrm{~m}, 3 \mathrm{H}), 4.21(\mathrm{~d}, J=7.1 \mathrm{~Hz}, 1 \mathrm{H}), 3.97$ (d, $J=15.6 \mathrm{~Hz}, 1 \mathrm{H}), 3.89$ (d, $J=15.6 \mathrm{~Hz}$, $1 \mathrm{H}), 3.70$ (s, $3 \mathrm{H}), 2.30-2.42$ (m, $2 \mathrm{H}), 2.10-2.23$ (m, $3 \mathrm{H}), 2.04$ (q, J = 6.9 Hz, $2 \mathrm{H}), 1.34$ $(\mathrm{d}, J=7.5 \mathrm{~Hz}, 3 \mathrm{H}), 1.32(\mathrm{~d}, J=7.5 \mathrm{~Hz}, 3 \mathrm{H}), 0.99(\mathrm{~d}, J=3.5 \mathrm{~Hz}, 3 \mathrm{H}), 0.97$ (d, $J=3.1$ $\mathrm{Hz}, 3 \mathrm{H}) ; .{ }^{13} \mathrm{C}$ NMR $\left(100 \mathrm{MHz}, \mathrm{CD}_{3} \mathrm{OD}\right) \delta 175.1,174.9,173.9,173.8,171.4,146.4$, $134.4,130.8,128.9,127.7,70.7,67.8,60.1,52.5,50.7,44.7,41.8,32.6,32.4,32.0,19.7$, 18.6, 17.7, 17.6; LRMS (ES+) $m / z 753.4\left(100 \%, \quad[\mathrm{M}+\mathrm{Na}]^{+}\right) ;$HRMS (ES+) $\mathrm{C}_{40} \mathrm{H}_{50} \mathrm{~N}_{4} \mathrm{O}_{7} \mathrm{SNa}$ Calcd. 753.3292, found 753.3307.

$(6 R, 9 R, 12 R, 16 S)$-6-Isopropyl-9,12-dimethyl-16-((E)-4-tritylsulfanyl-but-1-enyl)-1oxa-4,7,10,13-tetraaza-cyclohexadecane-2,5,8,11,14-pentaone 14: At $0^{\circ} \mathrm{C}$ to a stirred solution of $13(506 \mathrm{mg}, 0.69 \mathrm{mmol})$ in THF $(16 \mathrm{~mL})$ was added a solution of lithium hydroxide (33 mg, $1.39 \mathrm{mmol}$ ) in $\mathrm{H}_{2} \mathrm{O}(4 \mathrm{~mL})$. After $2 \mathrm{~h}$ the solution was diluted with $\mathrm{H}_{2} \mathrm{O}(10 \mathrm{~mL})$, acidified to $\mathrm{pH} 3$ with $1 \mathrm{M}$ potassium hydrogensulphate and extracted with EtOAc $(3 \times 15 \mathrm{~mL})$. The combined organic fractions were washed with saturated brine solution $(10 \mathrm{~mL})$ and dried with $\mathrm{Na}_{2} \mathrm{SO}_{4}$. The solvent was removed to give the crude acid $(555 \mathrm{mg})$ as an off-white solid. At rt to a solution of MNBA (265 mg, $0.77 \mathrm{mmol})$ and 
DMAP (188 mg, $1.54 \mathrm{mmol})$ in $\mathrm{CH}_{2} \mathrm{Cl}_{2}(160 \mathrm{~mL})$ was added dropwise over $2 \mathrm{~h}$ a solution of the crude acid (494 mg, $0.69 \mathrm{mmol})$ in $\mathrm{THF} / \mathrm{CH}_{2} \mathrm{Cl}_{2}(1: 2,600 \mathrm{~mL})$. After complete addition, the yellow solution was stirred for a further $8 \mathrm{~h}$. The solvent was concentrated to $<100 \mathrm{~mL}$ before being quenched with the addition of $1 \mathrm{M} \mathrm{HCl}(80 \mathrm{~mL})$ followed by EtOAc $(200 \mathrm{~mL})$. The resulting phases were separated and the organic phase was washed sequentially with saturated $\mathrm{NaHCO}_{3}$ solution $(50 \mathrm{~mL})$ and saturated brine solution $(50 \mathrm{~mL})$. The organic phase was dried with $\mathrm{Na}_{2} \mathrm{SO}_{4}$ and the solvent removed, to generate a crude product, which was then purified by flash chromatography (eluent $100 \%$ EtOAc then 5-10\% $\mathrm{MeOH} / \mathrm{CH}_{2} \mathrm{Cl}_{2}$ ) to generate an orange solid 14 (190 mg, 39\% yield). IR $v_{\max } 3314,2961,1738,1671,1630,1522,1206 \mathrm{~cm}^{-1} ;{ }^{1} \mathrm{H}$ NMR (400 MHz, $\left.\mathrm{CD}_{3} \mathrm{OD}\right)$ : ঠ. 7.19-7.38 (m, $14 \mathrm{H}), 5.60-5.67(\mathrm{~m}, 1 \mathrm{H}), 5.36-5.44(\mathrm{~m}, 2 \mathrm{H}), 4.41(\mathrm{~d}, J=17.1 \mathrm{~Hz}, 1 \mathrm{H})$, $4.28(\mathrm{~d}, J=5.1 \mathrm{~Hz}, 1 \mathrm{H}), 4.06$ (pentet, $J=7.2 \mathrm{~Hz}, 2 \mathrm{H}), 3.57(\mathrm{~d}, J=17.1 \mathrm{~Hz}, 1 \mathrm{H}), 2.50-$ 2.59 (m, 2 H), $2.43(\mathrm{dd}, J=10.0,15.1 \mathrm{~Hz}, 1 \mathrm{H}), 2.18(\mathrm{t}, J=7.1 \mathrm{~Hz}, 2 \mathrm{H}), 2.03(\mathrm{q}, J=7.2$ $\mathrm{Hz}, 2 \mathrm{H}), 1.52(\mathrm{~d}, J=7.5 \mathrm{~Hz}, 3 \mathrm{H}), 1.42(\mathrm{~d}, J=7.1 \mathrm{~Hz}, 3 \mathrm{H}), 0.97(\mathrm{~d}, J=7.1 \mathrm{~Hz}, 3 \mathrm{H})$, 0.94 (d, $J=7.1 \mathrm{~Hz}, 3 \mathrm{H}) ;{ }^{13} \mathrm{C}$ NMR (100 MHz, $\left.\mathrm{CD}_{3} \mathrm{OD}\right): \delta 175.8,175.5,172.8,171.4$, $169.5,145.9,133.7,130.5,129.1,128.7,127.5,73.5,67.5,59.8,53.5,51.2,42.5,41.3$, $32.1,32.0,30.0,19.9,17.9,17.3,16.5$; LRMS (ES+) $\mathrm{m} / \mathrm{z} 721.5\left(100 \%,[\mathrm{M}+\mathrm{Na}]^{+}\right)$; HRMS (ES+) $\mathrm{C}_{39} \mathrm{H}_{46} \mathrm{~N}_{4} \mathrm{O}_{6} \mathrm{SNa}$ Calcd. 721.3030, found 721.3017 .

$(6 R, 9 R, 12 R, 16 S)-6-$ Isopropyl-16-((E)-4-mercapto-but-1-enyl)-9,12-dimethyl-1oxa-4,7,10,13-tetraaza-cyclohexadecane-2,5,8,11,14-pentaone 15a: To a stirred solution of $14(50 \mathrm{mg}, 0.07 \mathrm{mmol})$ and $\mathrm{Et}_{3} \mathrm{SiH}(23 \mu \mathrm{L}, 0.14 \mathrm{mmol})$ in $\mathrm{CH}_{2} \mathrm{Cl}_{2}(1 \mathrm{~mL})$ was added TFA $(1 \mathrm{~mL})$. The reaction mixture was stirred at $\mathrm{rt}$ for $1 \mathrm{~h}$. The solution was concentrated and toluene $(10 \mathrm{~mL})$ was added, then the solution was re-concentrated. The 
crude product was purified by flash chromatography (eluent $5-10 \% \mathrm{MeOH} / \mathrm{CH}_{2} \mathrm{Cl}_{2}$ ) to give 15a (12.8 mg, 39\% yield) as a white solid: IR $v_{\max } 3316,2962,2931,1674,1633$, $1520,1210 \mathrm{~cm}^{-1} ;{ }^{1} \mathrm{H}$ NMR $\left(400 \mathrm{MHz}, \mathrm{CD}_{3} \mathrm{OD}\right) \delta 5.78(\mathrm{td}, J=7.2,14.5 \mathrm{~Hz}, 1 \mathrm{H}), 5.50-$ 5.60 (m, 2 H), 4.54 (brs, $3 \mathrm{H}), 4.41$ (d, $J=17.1 \mathrm{~Hz}, 1 \mathrm{H}), 4.29$ (d, $J=5.5 \mathrm{~Hz}, 1 \mathrm{H}), 4.08$ 4.10 (m, 2 H), 3.61 (d, $J=17.1 \mathrm{~Hz}, 1 \mathrm{H}), 2.64$ (dd, $J=3.2,14.8 \mathrm{~Hz}, 1 \mathrm{H}), 2.47-2.56$ (m, 5 H), $2.33(\mathrm{q}, J=6.7 \mathrm{~Hz}, 2 \mathrm{H}), 1.53(\mathrm{~d}, J=7.5 \mathrm{~Hz}, 3 \mathrm{H}), 1.44(\mathrm{~d}, J=7.5 \mathrm{~Hz}, 3 \mathrm{H}), 0.98$ (dd, $J=2.0,7.1 \mathrm{~Hz}, 6 \mathrm{H}) ;{ }^{13} \mathrm{C}$ NMR $\left(100 \mathrm{MHz}, \mathrm{CD}_{3} \mathrm{OD}\right) . \delta 176.1,175.9,173.2,171.8$, $169.8,133.5,130.2,74.0,60.0,53.7,51.5,42.7,41.7,37.4,30.2,24.3,20.0,18.0,17.3$, 16.6; LRMS (ES+) m/z $457.3\left(80 \%,[\mathrm{M}+\mathrm{H}]^{+}\right), 479.3\left(100 \%,[\mathrm{M}+\mathrm{Na}]^{+}\right), 935.8(50 \%$, $\left.[2 \mathrm{M}+\mathrm{Na}]^{+}\right)$; $455.3\left(100 \%,[\mathrm{M}-\mathrm{H}]^{-}\right)$; HRMS (ES+) $\mathrm{C}_{20} \mathrm{H}_{32} \mathrm{~N}_{4} \mathrm{O}_{6} \mathrm{SNa}$ Calcd. 479.1935, found 479.1937 .

Thioacetic acid S-[(E)-4-((6R,9R,12R,16S)-6-isopropyl-9,12-dimethyl-2,5,8,11,14pentaoxo-1-oxa-4,7,10,13-tetraaza-cyclohexadec-16-yl)-but-3-enyl] ester 15b: To a stirred solution of $14(47 \mathrm{mg}, 67 \mu \mathrm{mol})$ in anhydrous $\mathrm{CH}_{2} \mathrm{Cl}_{2}(1.7 \mathrm{~mL})$ was added $\mathrm{Et}_{3} \mathrm{SiH}$ $(21 \mu \mathrm{L}, 0.134 \mathrm{mmol})$ and TFA $(0.33 \mathrm{~mL})$. After stirring at room temperature for 15 minutes under inert atmosphere, the reaction solution was concentrated and the residue dried by high vacuum. Without further purification, the crude thiol 15a was used in next step. At $0{ }^{\circ} \mathrm{C}$, to a stirred solution of $\mathbf{1 5 a}$ in $\mathrm{CH}_{2} \mathrm{Cl}_{2}(4 \mathrm{~mL})$ was added $\mathrm{Et}_{3} \mathrm{~N}(48 \mu \mathrm{L}, 0.336$ mmol) and $\mathrm{AcCl}(14 \mu \mathrm{L}, 0.196 \mathrm{mmol})$. After 30 minutes the reaction mixture was warmed to $\mathrm{rt}$ and stirred for a further $1.5 \mathrm{~h}$, whereupon it was quenched by addition of sat. aq $\mathrm{NH}_{4} \mathrm{Cl}(5 \mathrm{~mL}) . \mathrm{CH}_{2} \mathrm{Cl}_{2}(60 \mathrm{~mL})$ was added to dilute the solution, phases separated, and the aqueous phase extracted with $\mathrm{CH}_{2} \mathrm{Cl}_{2}(3 \times 10 \mathrm{~mL})$. The combined organic phases were washed with sat. aq $\mathrm{NaCl}(5 \mathrm{~mL})$, dried $\left(\mathrm{MgSO}_{4}\right)$, filtered, and 
concentrated. The residue was purified by flash chromatography (eluent: 5-10\% MeOH/ $\left.\mathrm{CH}_{2} \mathrm{Cl}_{2}\right)$ to give compound $\mathbf{1 5 b}(15.8 \mathrm{mg}, 32 \mu \mathrm{mol}, 47 \%)$ as a white solid: $[\alpha]_{\mathrm{D}}{ }^{27}=2.0$ (c, 0.34, $\mathrm{CHCl}_{3} / \mathrm{MeOH}=4 / 1$ ); IR $v_{\max } 3322,2965,1744,1674,1633,1520,1212,797$, $623 \mathrm{~cm}^{-1} ;{ }^{1} \mathrm{H}$ NMR (400 MHz, $\left.\mathrm{CDCl}_{3} / 5 \% \mathrm{CD}_{3} \mathrm{OD}\right) \delta .5 .60-5.70(\mathrm{~m}, 1 \mathrm{H}), 5.38-5.50$ (m, 2 H), $4.37(\mathrm{~d}, J=17.0 \mathrm{~Hz}, 1 \mathrm{H}), 4.27(\mathrm{~d}, J=5.0 \mathrm{~Hz}, 1 \mathrm{H}), 4.04(\mathrm{q}, J=7.0 \mathrm{~Hz}, 1 \mathrm{H}), 3.94$ (q, $J=7.2 \mathrm{~Hz}, 1 \mathrm{H}), 3.73(\mathrm{~s}, 1 \mathrm{H}), 3.52-3.58(\mathrm{~m}, 1 \mathrm{H}), 3.05(\mathrm{~d}, J=4.5 \mathrm{~Hz}, 2 \mathrm{H}), 2.90(\mathrm{t}$, $J=7.2 \mathrm{~Hz}, 2 \mathrm{H}), 2.35-2.50(\mathrm{~m}, 2 \mathrm{H}), 2.25(\mathrm{~s}, 3 \mathrm{H}), 2.22(\mathrm{q}, J=7.5 \mathrm{~Hz}, 1 \mathrm{H}), 1.53(\mathrm{~d}, J=$ $7.0 \mathrm{~Hz}, 3 \mathrm{H}), 1.35$ (d, $J=7.0 \mathrm{~Hz}, 3 \mathrm{H}), 0.92(\mathrm{~d}, J=7.5 \mathrm{~Hz}, 3 \mathrm{H}), 0.90$ (d, $J=7.0 \mathrm{~Hz}, 3$ $\mathrm{H}) ;{ }^{13} \mathrm{C} \mathrm{NMR}\left(100 \mathrm{MHz}, \mathrm{CDCl}_{3} / 5 \% \mathrm{CD}_{3} \mathrm{OD}\right) \delta 196.3,174.4,173.9,171.6,170.2,168.8$, $132.2,128.6,72.4,58.5,54.8,53.2,41.6,41.1,32.0,30.5,28.8,28.1,19.4,17.1,16.8$, 16.4; LRMS (ES+) m/z $521.4\left(100 \%,[\mathrm{M}+\mathrm{Na}]^{+}\right), 1019.9\left(18 \%,[2 \mathrm{M}+\mathrm{Na}]^{+}\right)$; HRMS (ES+) $\mathrm{C}_{22} \mathrm{H}_{34} \mathrm{~N}_{4} \mathrm{O}_{7} \mathrm{SNa}$ Calcd. 521.2040, found 521.2047.

MCF7 growth inhibition assay. MCF7 (ECACC, Salisbury, UK) breast cancer cells were maintained in Dulbecco's Modified Eagles Medium (Cambrex, Wokingham, UK) with 10\% (v/v) foetal calf serum (FCS) (PAA laboratories, Pasching, Austria), $100 \mu \mathrm{g} / \mathrm{ml}$ Penicillin G, $100 \mu \mathrm{g} / \mathrm{ml}$ Streptomycin and $292 \mu \mathrm{g} / \mathrm{ml}$ L-glutamine (all from Cambrex) at $37{ }^{0} \mathrm{C}$ in $10 \%(\mathrm{v} / \mathrm{v}) \mathrm{CO}_{2}$.

MCF7 breast cancer cells were plated in 96 well plates, at a density of 1000 cells in $100 \mu 1$ of cell culture medium per well. Compounds were added a minimum of 5 hours later, in serial dilutions in cell culture medium, in $100 \mu \mathrm{l}$ volumes at $2 \mathrm{x}$ final concentration. Cell culture medium was removed 6 days by inversion of the plate onto blotting paper and cells were gently washed once with $200 \mu$ PBS. Plates were frozen 
immediately for a minimum of one hour at $-80^{\circ} \mathrm{C}$ and then thawed. Cell proliferation assays were then performed using the CyQuant TM assay system (Molecular Probes, OR, USA) according to the manufacturer's instructions. Cell proliferation was determined for mean values of duplicate samples as percentages relative to untreated cell samples $(=100 \%)$. Non-linear regression was performed using GraphPad Prism Software to determine an $\mathrm{IC}_{50}$ (GraphPad Software, San Diego, CA, US).

Inhibition of total HDACs from HeLa cell extracts. In vitro HDAC assays were performed using a HDAC fluorescent activity assay kit (Biomol, Exeter, UK) according to the manufacturer's instructions. In most assays, compounds were reduced prior to analysis; $1 \mathrm{mM}$ compound was reduced with $30 \mathrm{mM}$ DTT in DMSO overnight at room temperature, protected from light. To test the effect of DTT on the activity of 15a, assays were performed using DTT-treated or unreduced compound and with a HeLa cell lysate that had been prepared in the absence of DTT (a kind gift of Ian Varndell, BioMol, Exeter, UK). Inhibition of HDAC activity was determined for mean values of duplicate samples as a percentage of untreated samples. Non-linear regression was performed using GraphPad Prism Software to determine an $\mathrm{IC}_{50}$ (GraphPad Software, San Diego, CA, US).

Inhibition of HDAC1 and HDAC6. Enzyme assays with partially purified HDAC1 and HDAC6 were caried out according to published protocols: Bhuiyan, M. P. I.; Kato, T.; Okauchi, T.; Nishino, N.; Maeda, S.; Nishino, T. G.; Yoshida, M. Bioorg. Med. Chem. 2006, 14, 3438-3446.

Induction of histone acetylation. The effect of 8a on histone acetylation were determined by immunoblotting. MCF7 cells were treated with 8a or solvent control 
(DMSO) for 16 hours. Cells were collected by scraping and centrifugation, washed in PBS and lysed in protein sample buffer supplemented with DTT (New England Biolabs). Genomic DNA was sheared by brief sonication and the sample was heated to $95{ }^{\circ} \mathrm{C}$ for 5 minutes before being resolved by SDS-polyacrylamide gel electrophoresis. Immunoblotting was performed as previously described (Packham et al., Mammalian cells express two differently localized Bag-1 isoforms generated by alternative translation initiation. Biochem J. 1997 328:807-13) using a rabbit anti-acetylated histone H4 antibody (Upstate Biotech). Acteylated histone H4 was undetectable in control MCF7 cells, or cells exposed to solvent alone as a control, but was abundant in cells exposed to 8a.

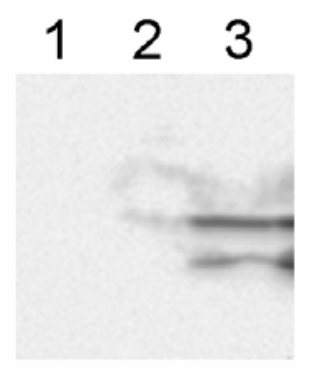

Figure 4. Accumulation of acetylated histone $\mathrm{H} 4$ in MCF7 breast cancer cells. 1, untreated cells; 2, solvent control (DMSO); 3, 8a (250 nM).

Induction of promoter activity. We also analysed the effects of compounds on activity of the $\mathrm{p} 21^{\text {wafl/cip1 }}$ promoter which has previously been demonstrated to be activated in cells treated with HDAC inhibitors (Huang L, Sowa Y, Sakai T, Pardee AB, Activation of the $\mathrm{p} 21 \mathrm{WAF} 1 / \mathrm{CIP} 1$ promoter independent of $\mathrm{p} 53$ by the histone deacetylase inhibitor suberoylanilide hydroxamic acid (SAHA) through the Sp1 sites. Oncogene. 2000 19:5712-9). MCF7 cells were transfected with a p21 promoter 
luciferase construct (pWWP) and a beta-galactosidase expression construct to correct for variation in transfection efficiencies. Transfections were performed using the TransFast reagent (Promega) according to the manufacturer's instructions. The cells were allowed to recover overnight before being treated with compounds. After 24 hours, cells were harvested and luciferase and beta-galactosidase activity determined using standard assays.

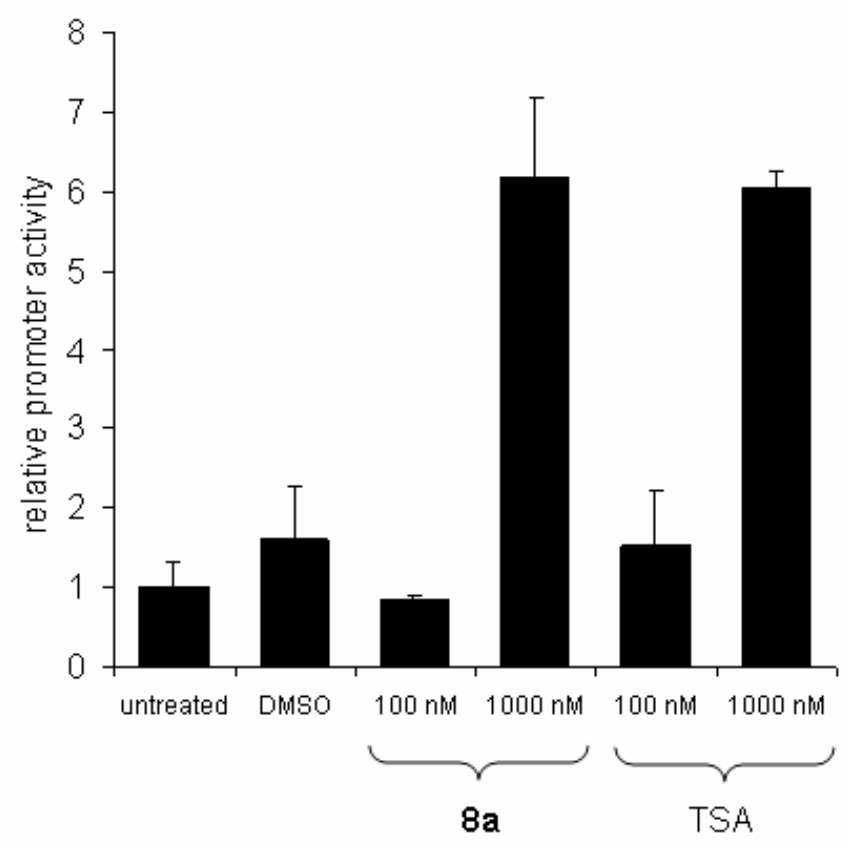

Figure 5. Induction of $\mathrm{p} 21^{\text {waf1/cip1 }}$ promoter activity. 